\title{
Analysis of the friction term in the one-dimensional
}

\author{
shallow-water model
}

\section{J. Burguete ${ }^{1}$, P. García-Navarro ${ }^{2}$, J. Murillo ${ }^{3}$ and I. García-Palacín ${ }^{4}$}

March 29, 2007

\begin{abstract}
The numerical simulation of unsteady open channel flows is very commonly performed using the one-dimensional shallow-water model. Friction is one of the relevant forces included in the momentum equation. In this work, a generalization of the Gauckler-Manning friction model is proposed to improve the modeling approach in cases of dominant roughness, unsteady flow and distorted cross sectional shapes. The numerical stability conditions are revisited in cases of dominant friction terms and a new condition, complementary to the basic CFL condition, is proposed. Some test cases with measured data are used to validate the quality of the approaches.
\end{abstract}

CE database subject headings: Shallow water, Open channels, Flow resistance, Roughness, Numerical models, Energy losses.

\footnotetext{
${ }^{1}$ Researcher. Suelo y agua. Estación Experimental Aula Dei. CSIC. Avda. Montañana 1005, 50059 Zaragoza. Spain. E-mail: jburguete@eead.csic.es

${ }^{2}$ Lecturer. Fluid Mechanics. CPS. University of Zaragoza. María de Luna 3, 50018 Zaragoza. Spain. E-mail: pigar@unizar.es

${ }^{3}$ Assistant Professor. Fluid Mechanics. CPS. University of Zaragoza. María de Luna 3, 50018 Zaragoza. Spain. E-mail: jmurillo@mafalda.cps.unizar.es

${ }^{4}$ Lecturer. Fluid Mechanics. CPS. University of Zaragoza. María de Luna 3, 50018 Zaragoza. Spain. E-mail: ignacio@unizar.es
} 


\section{Introduction}

The one-dimensional shallow-water model involves cross-sectional averaging of the original flow equations if not only trivial situations have to be handled. One of the main consequences of such cross sectional averaging is that the viscous flow boundary condition at solid walls and bottom is transformed into a drag/friction force source term. The form of this friction force term is closely related to the assumed velocity profile and therefore to the underlying turbulence model.

To model friction, empirical or semi-empirical methods have traditionally been applied (Darcy 1858; Gauckler 1867; Manning 1890). They are all dependent on the surface roughness as well as on the flow characteristics, and their coefficients can be found in tabular form in many references as, for instance, (Chow 1959). Several authors have reported experimental studies devoted to measuring the friction force in the presence of bed roughness. A few of them extracted data correlations different than the standard Gauckler-Manning's law (Smart et al. 2002; Kellerhals 1967; Bathurst et al. 1981) and some authors reported a Gauckler-Manning coefficient dependent on the water depth (Jarrett 1984). Smart (1999) proposed a friction model based on a logarithmic velocity profile.

There is a necessity to improve the friction models in highly rough and dry natural or artificial channels such as creeks, mountain rivers or furrows. Steady and unsteady experiments of flow in a border were reported in (García-Navarro et al. 2000) as well as the necessity of using very different Gauckler-Manning coefficients in order to reproduce observations with a single one-dimensional model. The work presented in this paper is a contribution motivated by two aims. Our first objective is to produce a friction model, based on a power-law velocity profile, trying to retain as much as possible the conceptual simplicity and the asymptotic convergence to the Gauckler-Manning's law at low roughness values but more general in other conditions. The second objective is related with the incorporation of the friction forces into numerical simulation models.

In cases of channel or river flow with overbank sections as well as those with non-uniform cross section bed roughness, the traditional hypothesis of uniform velocity is unrealistic. It becomes necessary to perform a decomposition of the channel cross section in subsections as, for instance, suggested in (Chow 1959; Cunge et al. 1980; Knight 2006; Cao et al. 2006). This procedure is based 
on the assumption of a single cross sectional energy slope and may lead to contradictions (Cunge et al. 1980; Knight 2006). The validity of this approximation has not been sufficiently analyzed. Two cross sectional decomposition models based on extremal hypotheses are considered: a minimization of the frictional energy loss and a minimization of the total friction stress. The different approaches will be compared against measured data.

The friction term participates in the Saint-Venant mathematical model as a non-linear sink of momentum. The system is a set of partial differential equations that requires numerical solution in almost all cases of practical interest. Therefore, a complete analysis of the role played by friction in an open channel flow model does involve the question of the numerical simulation as well as those of the mathematical modeling. Our second objective is to evaluate the interaction between a dominant friction term in the equations and stability constraints within a model at the discrete level. Conventional numerical stability conditions are based on the predominance of convective terms and may not be sufficient in cases of high roughness. In many cases, experience indicates that a spatial grid refinement and a time step size reduction become necessary to achieve stable solutions. Liggett and Cunge (1997) proposed a time step limit dictated by the friction coefficient. Even though this criterion may contribute to stability in some cases, it is shown to not be a reliable condition in general cases of flow over rough, irregular beds. A more general condition leading to a requirement on the spatial grid size will be derived and tested in a real case.

\section{Basic equations}

1D open channel flow can be modelled using the Saint-Venant equations (Saint-Venant 1871). The conservative form of these equations can be expressed in vector form as:

$$
\frac{\partial \mathbf{u}}{\partial t}+\frac{\partial \mathbf{F}}{\partial x}=\mathbf{H}
$$

with $\mathbf{u}$ the conserved variable, and $\mathbf{F}$ and $\mathbf{H}$ the conservative flux and source terms respectively:

$$
\mathbf{u}=\left(\begin{array}{c}
A \\
Q
\end{array}\right), \quad \mathbf{F}=\left(\begin{array}{c}
Q \\
\frac{\beta Q^{2}}{A}+g I_{1}
\end{array}\right), \quad \mathbf{H}=\left(\begin{array}{c}
0 \\
g\left(I_{2}+A S_{0}\right)-T
\end{array}\right)
$$


where $A$ is the wetted cross section, $Q$ the discharge, $g$ the gravitational acceleration, $S_{0}$ the main bed slope, $T$ the friction stress over the solid surface in the channel reach, $\beta$ is a coefficient that appears as a result of the assumption of variable velocity in the cross section:

$$
\beta=\frac{A}{Q^{2}} \int_{A} u^{2} d A
$$

with $u=u(x, y, z, t)$ the local point flow velocity, and $I_{1}, I_{2}$ pressure forces:

$$
I_{1}=\int_{0}^{H} \sigma\left(x, z^{\prime \prime}\right)\left(H-z^{\prime \prime}\right) d z^{\prime \prime}, \quad I_{2}=\int_{0}^{H} \frac{\partial \sigma\left(x, z^{\prime \prime}\right)}{\partial x}\left(H-z^{\prime \prime}\right) d z^{\prime \prime}
$$

with $H$ the maximum water depth at the cross section and $\sigma$ the section width at a level $z^{\prime \prime}$ with reference to the minimum bottom level $z_{b}$ (see Figure 1).

The flux Jacobian is:

$$
\mathbf{J}=\frac{\partial \mathbf{F}}{\partial \mathbf{u}}=\left(\begin{array}{cc}
0 & 1 \\
c^{2}-\beta \bar{u}^{2} & 2 \beta \bar{u}
\end{array}\right)
$$

with $\bar{u}=Q / A$ the average flow velocity and $c=\sqrt{g A / B}$ the celerity of the infinitesimal waves, where $B$ is the cross sectional top width. The eigenvalues of this Jacobian are:

$$
\lambda_{1}=\beta \bar{u}+\sqrt{\left(\beta^{2}-\beta\right) \bar{u}^{2}+c^{2}}, \quad \lambda_{2}=\beta \bar{u}-\sqrt{\left(\beta^{2}-\beta\right) \bar{u}^{2}+c^{2}}
$$

The matrices that diagonalize this Jacobian are:

$$
\mathbf{P}=\left(\begin{array}{cc}
1 & 1 \\
\lambda_{1} & \lambda_{2}
\end{array}\right), \quad \boldsymbol{\Lambda}=\left(\begin{array}{cc}
\lambda_{1} & 0 \\
0 & \lambda_{2}
\end{array}\right), \quad \mathbf{J}=\mathbf{P} \boldsymbol{\Lambda} \mathbf{P}^{-1}
$$

The Jacobian of the source term is:

$$
\mathbf{K}=\frac{\partial \mathbf{H}}{\partial \mathbf{u}}=\left(\begin{array}{cc}
0 & 0 \\
-g\left(\frac{\partial z_{s}}{\partial x}-\frac{1}{B} \frac{\partial A}{\partial x}\right)-\frac{\partial T}{\partial A} & -\frac{\partial T}{\partial Q}
\end{array}\right)
$$

with $z_{s}$ the water surface level. 


\section{Local friction models}

\section{Gauckler-Manning friction model}

In the empirical Gauckler-Manning model, the friction slope $S_{f}$ can be expressed in SI units as (Gauckler 1867; Manning 1890):

$$
S_{f}=\frac{T}{g A}=\frac{n^{2}|Q| Q}{A^{2} R^{\frac{4}{3}}}
$$

with $R=A / P$ the hydraulic radius, $P$ the wetted perimeter and $n$ the Gauckler-Manning coefficient. A kinematic friction stress $\tau$ at a point in this model can be defined as:

$$
\tau d P=g n^{2}|U| U h^{-\frac{1}{3}} d y
$$

with $h=H-z^{\prime}$ the local water depth, $z^{\prime}$ the local bottom level with respect to the minimum bottom level in the cross section (see Figure 1), $U$ the depth-averaged water velocity and $y$ the transversal coordinate.

\section{Kellerhals friction model}

In the empirical Kellerhals gravel-bed rivers model, the friction slope $S_{f}$ can be expressed in SI units as (Kellerhals 1967):

$$
S_{f}=\frac{r^{2}|Q| Q}{A^{2} R^{\frac{3}{2}}}, \quad T=g A S_{f}=\frac{g r^{2} Q|Q|}{A R^{\frac{3}{2}}}
$$

with $r$ the Kellerhals roughness coefficient.

\section{Darcy-Weisbach friction model}

In the Darcy-Weisbach model, the friction slope is expressed as:

$$
S_{f}=\frac{f Q|Q|}{8 g R A^{2}}, \quad T=g A S_{f}=\frac{f Q|Q|}{8 R A}
$$

with $f$ the dimensionless Darcy-Weisbach friction factor. 


\section{Power-law velocity model}

We shall assume that the velocity profile can be fit by means of a power function in the roughness upper zone, being negligible in the lower zone:

$$
u(x, y, z, t)=u_{l}(x, y, t)\left(\frac{\zeta}{l}\right)^{b}, \text { if } \zeta \geq l
$$

where $\zeta=z-z_{b}-z^{\prime}$ is the vertical distance to the bottom level, $b$ is a fitting exponent and $u_{l}(x, y, t)$ is the water velocity at a distance $l$ of the bed, as represented in Figure 2. We shall also assume that the bed roughness irregularities are of average size $l$ or, in smooth channels, $l$ can be identified with the viscous sublayer thickness. We shall postulate that the exponent $b$ only depends on the flow characteristics and the relative roughness $l / h$. For $h>l, U$ is defined as:

$$
U=\frac{1}{h} \int_{0}^{h} u d \zeta=\frac{1}{h} \int_{l}^{h} u d \zeta=\frac{u_{l}}{b+1}\left(\frac{h}{l}\right)^{b}\left[1-\left(\frac{l}{h}\right)^{1+b}\right]
$$

If the flow can be considered fully turbulent, as in most channel and river flow situations:

$$
\tau d P \approx \epsilon u_{l}^{2} d y
$$

with $\epsilon$ a dimensionless aerodynamic constant dependent on the roughness characteristics and the Reynolds number. Expressing this in terms of the average velocity (14), the friction stress of this model is:

$$
\tau d P \approx \epsilon(b+1)^{2} U^{2}\left(\frac{l}{h}\right)^{2 b}\left[1-\left(\frac{l}{h}\right)^{1+b}\right]^{-2} d y, \text { if } h>l
$$

This friction law is only valid for $h>l$. If $h<l$ a zero velocity condition is imposed for numerical stabilization of the advance over a dry bed.

Smart (1999), using a similar procedure, derived another expression starting from a logarithmic velocity profile assumption. Earlier work is available (White 1991) to find a similar development using a power-law velocity profile, but not including the existence of a sublayer of thickness $l$ where the velocity is negligible. In our power-law model a new factor $\left[1-(l / h)^{1+b}\right]^{-2}$ appears so that the friction increases in cases of high relative roughness up to a singular value for $h=l$. This result is in good agreement with the rough beds empirical laws that predict increasing Gauckler-Manning coefficients for decreasing water depths (Jarrett 1984; García-Navarro et al. 2000). 
For low roughness and turbulent flow, Prandtl, according to (White 1991), proposed the use of a velocity profile:

$$
l \rightarrow 0 \Rightarrow \quad b=\frac{1}{7}
$$

In cases of open channels and natural rivers with low relative roughness $(l \ll h)$ the expression tends to the Gauckler-Manning (10) model provided that:

$$
g n^{2}=\epsilon(b+1)^{2} l^{2 b}, \quad b=\frac{1}{6}
$$

$n$ depends on the relative roughness in the same way that (Strickler 1923) does for soil grain roughness:

$$
n=0.041\left(d_{50}\right)^{\frac{1}{6}}
$$

with $d_{50}$ the bed particle size mean diameter. In this form, the Gauckler-Manning model can be associated with a vertical velocity profile of the type (13) in the form:

$$
u(\zeta)=u(h)\left(\frac{\zeta}{h}\right)^{\frac{1}{6}}
$$

Considering $d_{50} \approx l,(18)$ and $(19)$ provide also an estimation of the parameter $\epsilon$ for granulometric roughness:

$$
\epsilon=\frac{g n^{2}}{(b+1)^{2}\left(d_{50}\right)^{2 b}} \approx 0.012
$$

Values of $b$ greater than $1 / 6$ can be required for higher relative roughness in order to make the model equivalent to other models proposed in these situations (Smart et al. 2002; Kellerhals 1967; Bathurst et al. 1981). It is, at the same time, easy to estimate provided that experimental data of the velocity vertical profile are available.

\section{Friction models in irregular or compound sections}

The hypothesis of uniform cross sectional velocity, basic in the standard one-dimensional GaucklerManning model (9), may not be valid in real cases, mainly in rivers with adjacent floodplain flow in which there is a strong difference between the velocity in the main channel and that over the floodplain, in cases of irregular cross section shapes or in cases of variable roughness. Two-dimensional 
models, not based on cross sectional uniformity, provide a better representation of the role played by friction in these cases. It is not obvious what is the correct form to incorporate a cross sectional variability of the frictional coefficient in one-dimensional models. In these cases, the constant friction slope model is widely used (Chow 1959; Cunge et al. 1980). Other formulations can be found in (Knight 2006; Cao et al. 2006).

We shall try to extend the one-dimensional model trying to produce a simple approach. In this sense, we seek a model less refined than (Shiono et al. 1999), who model lateral exchange of momentum requiring the solution of a differential equation in the transversal direction and therefore becomes excessively complex for our purpose. The lateral exchange of momentum is neglected in our approach. The main hypothesis will be that the wetted cross section is much wider than deep and our simplification will be supported by experimental evidence (McGahey et al. 2006) that the lateral exchange of momentum effects and secondary flows have a relative magnitude smaller than boundary friction effects in most rivers. In a simple prismatic channel the longitudinal slope $S_{0}$ is uniform in a cross section. If the gravity and friction forces are dominant and the flow is well developed $S_{f} \approx S_{0}$ can be also considered uniform in the whole cross section.

The hypothesis of minimization of energy losses is common in one-dimensional models (Bettess and White 1987; Knight 2006). For that purpose, we shall assume that the velocity distribution within a cross section is such that the frictional energy loss is minimum. In our formulation, two options have been identified to express the requirement of minimum frictional energy loss:

- $\int_{P} \tau U d P$ : This formulation considers the cross sectional energy loss as a sum of local energy losses and shall be named the minimization losses of energy (MLE) model.

- $T Q / A$ : Using this average quantity at a cross section, for given discharge and maximum water depth, the minimization of the energy loss is equivalent to the minimization of $T$. For that reason we shall call this option the minimization of total friction stress (MTFS) model. 


\section{Minimization losses of energy (MLE) model}

Assuming locally valid the Gauckler-Manning model (10) or that of fitted velocity profile for low relative roughness (16), and dividing the cross section into vertical differential elements, the cross sectional friction stress and the discharge can be computed as the sums in every differential element:

$$
Q=\sum_{j} U_{j} h_{j} d y_{j}, \quad T=\sum_{j} g n_{j}^{2} U_{j}^{2} h_{j}^{-2 b} d y_{j}, \quad \int_{P} \tau U d P=\sum_{j} g n_{j}^{2} U_{j}^{3} h_{j}^{-2 b} d y_{j}
$$

Extracting now the mean velocity $U_{i}$ of the $i$-th differential element:

$$
\int_{P} \tau U d P=g n_{i}^{2}\left(\frac{Q-\sum_{j \neq i} U_{j} h_{j} d y_{j}}{h_{i} d y_{i}}\right)^{3} h_{i}^{-2 b} d y_{i}+\sum_{j \neq i} g n_{j}^{2} U_{j}^{3} h_{j}^{-2 b} d y_{j}
$$

In order to minimize $\int_{P} \tau U d P$, then:

$$
\frac{\partial}{\partial U_{k}}\left(\int_{P} \tau U d P\right)=3 g n_{i}^{2} U_{i}^{2} h_{i}^{-2 b} d y_{i}\left(\frac{-h_{k} d y_{k}}{h_{i} d y_{i}}\right)+3 g n_{k}^{2} U_{k}^{2} h_{k}^{-2 b} d y_{k}=0
$$

which yields the following condition for the velocity:

$$
U=\eta \frac{h^{b+(1 / 2)}}{n}
$$

that involves a $\eta=\eta(x, H, Q)$ constant in a cross section, for given discharge and maximum water depth. Integrating (25) in the cross section:

$$
Q=\sum_{i} \int_{y_{i}}^{y_{i+1}} h U d y=\eta \Psi
$$

with $\Psi$ a cross sectional discharge factor only depending on the maximum water depth:

$$
\Psi=\sum_{i} \psi_{i+(1 / 2),} \quad \psi_{i+(1 / 2)}= \begin{cases}\frac{h_{i}^{b+(3 / 2)}}{n_{i+(1 / 2)}} \delta y_{i+(1 / 2)}, & \text { if } h_{i}=h_{i+1} \\ \frac{1}{[b+(5 / 2)] n_{i+(1 / 2)}} \frac{h_{i+1}^{b+(5 / 2)}-h_{i}^{b+(5 / 2)}}{h_{i+1}-h_{i}} \delta y_{i+(1 / 2)}, & \text { if } h_{i} \neq h_{i+1}\end{cases}
$$

with the notation $\delta y_{i+(1 / 2)}=y_{i+1}-y_{i}$. Using (26) and (25) the cross sectional friction stress is:

$$
T=\sum_{i} \int_{y_{i}}^{y_{i+1}} \tau d P=\sum_{i} \int_{y_{i}}^{y_{i+1}} g n^{2} U|U| h^{-2 b} d y=\frac{g A|Q| Q}{\Psi^{2}}
$$

with the friction slope and the associated Darcy-Weisbach factor:

$$
S_{f}=\frac{Q|Q|}{\Psi^{2}}, \quad f=\frac{8 g R A^{2}}{\Psi^{2}}
$$


This expression can be found with a similar and simpler form in (Cunge et al. 1980), where the cross section was decomposed in rectangular vertical subsections. Here, the idea has been extended to a decomposition in trapezoidal vertical subsections.

This model enables the estimation of the parameter $\beta$. At low relative roughness, the power-law velocity and Gauckler-Manning models predict, at a given cross section, a vertical velocity profile in the form:

$$
u(y, \zeta) \approx u(y, h(y))\left(\frac{\zeta}{h(y)}\right)^{b}=(b+1) U\left(\frac{\zeta}{h(y)}\right)^{b}
$$

Using (25), integration in the cross section leads to:

$$
\beta=\frac{A}{Q^{2}} \int_{A} u^{2} d A=\frac{(b+1)^{2} A \sum_{i} \xi_{i+(1 / 2)}}{(2 b+1) \Psi^{2}}
$$

with:

$$
\xi_{i+(1 / 2)}= \begin{cases}\frac{h_{i}^{2+2 b}}{n_{i+(1 / 2)}^{2+2 b}} \delta y_{i+(1 / 2)}, & \text { if } h_{i}=h_{i+1} \\ \frac{1}{(3+2 b) n_{i+(1 / 2)}^{2}} \frac{h_{i+1}^{3+2 b}-h_{i}^{3+2 b}}{h_{i+1}-h_{i}} \delta y_{i+(1 / 2)}, & \text { if } h_{i} \neq h_{i+1}\end{cases}
$$

The expression (31) is again an extension of the one proposed in (Cunge et al. 1980) to a decomposition in trapezoidal vertical subsections that, at the same time, involves the factor $(b+1)^{2} /(2 b+1)$ due to our assumption of a vertically variable velocity profile.

The coefficients $\Psi$ and $\beta$ can be obtained from (27) and (31) but, in the case of complex cross sections, its calculation can become rather inefficient. In that case, and taking into account that $\Psi=\Psi(x, H)$ and $\beta=\beta(x, H)$ in a cross section depend exclusively on the maximum water depth, it is highly recommended to build a table of the coefficients for different water depth values and apply interpolation.

\section{Minimization of total friction stress (MTFS) model}

Extracting now the mean velocity $U_{i}$ of the $i$-th differential element and inserting it in (22):

$$
T=g n_{i}^{2}\left(\frac{Q-\sum_{j \neq i} U_{j} h_{j} d y_{j}}{h_{i} d y_{i}}\right)^{2} h_{i}^{-2 b} d y_{i}+\sum_{j \neq i} g n_{j}^{2} U_{j}^{2} h_{j}^{-2 b} d y_{j}
$$


As stated before, it will be assumed that the cross sectional velocity distribution is so that the total friction stress is minimum, therefore:

$$
\frac{\partial T}{\partial U_{k}}=2 g n_{i}^{2} U_{i} h_{i}^{-2 b} d y_{i}\left(\frac{-h_{k} d y_{k}}{h_{i} d y_{i}}\right)+2 g n_{k}^{2} U_{k} h_{k}^{-2 b} d y_{k}=0
$$

This equation holds provided that the velocity distribution satisfies:

$$
U=\eta \frac{h^{1+2 b}}{n^{2}}
$$

with $\eta=\eta(x, Q, H)$ constant in a cross section, for given discharge and maximum water depth as before.

Integration of (35) in the cross section gives:

$$
Q=\sum_{i} \int_{y_{i}}^{y_{i+1}} h U d y=\eta \Gamma
$$

with:

$$
\Gamma=\sum_{i} \gamma_{i+(1 / 2)}, \quad \gamma_{i+(1 / 2)}= \begin{cases}\frac{h_{i}^{2+2 b}}{n_{i+(1 / 2)}^{2}} \delta y_{i+(1 / 2)}, & \text { if } h_{i}=h_{i+1} \\ \frac{1}{(3+2 b)\left(n^{2}\right)_{i+(1 / 2)}} \frac{h_{i+1}^{3+2 b}-h_{i}^{3+2 b}}{h_{i+1}-h_{i}} \delta y_{i+(1 / 2)}, & \text { if } h_{i} \neq h_{i+1}\end{cases}
$$

Using (36) and (35) the cross sectional friction stress is:

$$
T=\sum_{i} \int_{y_{i}}^{y_{i+1}} \tau d P=\sum_{i} \int_{y_{i}}^{y_{i+1}} g n^{2} U|U| h^{-2 b} d y=\frac{g|Q| Q}{\Gamma}
$$

with the friction slope and the associated Darcy-Weisbach factor:

$$
S_{f}=\frac{|Q| Q}{A \Gamma}, \quad f=\frac{8 g R A}{\Gamma}
$$

The value of the parameter $\beta$ predicted by this model can be calculated from (30), (35), (36) and (3):

$$
\beta=\frac{(b+1)^{2} A \sum_{i} \xi_{i+(1 / 2)}}{(2 b+1) \Gamma^{2}}, \quad \xi_{i+(1 / 2)}= \begin{cases}\frac{h_{i}^{3+4 b}}{n_{i+(1 / 2)}^{4}} \delta y_{i+(1 / 2)}, & \text { if } h_{i}=h_{i+1} \\ \frac{1}{(4+4 b) n_{i+(1 / 2)}^{4}} \frac{h_{i+1}^{4+4 b}-h_{i}^{4+4 b}}{h_{i+1}-h_{i}} \delta y_{i+(1 / 2)}, & \text { if } h_{i} \neq h_{i+1}\end{cases}
$$

\section{Constant friction slope (CFS) model}

This model is based on the assumption that $S_{f}$ can be considered uniform in the whole cross section. Accepting that the Gauckler-Manning model (10) or the power-law velocity model for low roughness 
(16) are valid, the friction slope for a differential vertical subsection is defined as:

$$
S_{f}=n^{2} U|U| h^{-1-2 b} \approx \text { const. }
$$

so that, for a compound section as in Figure 3 with a constant Gauckler-Manning $n$ in every element:

$$
U=\eta \frac{h^{b+(1 / 2)}}{n}
$$

with $\eta=\eta(x, Q, H)$ constant in a cross section, for given discharge and maximum water depth as before. This velocity distribution over the cross section is identical to the one predicted by the MLE model (41). Following the steps of the previous subsections, this model provides identical laws (29) and (31) to the ones predicted by the MLE model.

Note also that MLE/CFS and MTFS models differ only in cases of non-rectangular cross section shape. In cases of rectangular cross section with uniform roughness:

- MLE/CFS models: $T=\frac{g A|Q| Q}{\Psi^{2}}=\frac{g n^{2}|Q| Q}{B H^{2+2 b}}$

- MTFS model: $T=\frac{g|Q| Q}{\Gamma}=\frac{g n^{2}|Q| Q}{B H^{2+2 b}}$

\section{Numerical schemes}

The conservative form of the system of differential equations (1) can be solved by means of a conservative scheme. The following vector is defined for convenience:

$$
\mathbf{G}_{i+(1 / 2)}=\left(\mathbf{H}-\frac{\delta \mathbf{F}}{\delta x}\right)_{i+(1 / 2)}
$$

The unified discretization of the friction term consists of discretizing flux, friction and other source terms in the equation in a similar form. A general conservative scheme with unified discretization can be expressed as (Burguete and García-Navarro 2001; Burguete and García-Navarro 2004a; Burguete and García-Navarro 2004b):

$$
\left(1-\theta \Delta t \mathbf{K}_{i}^{n}\right) \Delta \mathbf{u}_{i}^{n}=\Delta t\left(\mathbf{G}_{i-(1 / 2)}^{L}+\mathbf{G}_{i+(1 / 2)}^{R}\right)
$$

where $\mathbf{K}$ is the source term Jacobian, $\theta$ is a coefficient controlling the implicitness of the source term and $\mathbf{G}^{L, R}$ represents the wave discretization particular to each numerical scheme. 
Defining the upwind matrices:

$$
\boldsymbol{\Omega}^{ \pm}=\frac{1}{2} \mathbf{P}\left(\begin{array}{cc}
1 \pm \operatorname{sign}\left(\lambda_{1}\right) & 0 \\
0 & 1 \pm \operatorname{sign}\left(\lambda_{2}\right)
\end{array}\right) \mathbf{P}^{-1}
$$

The wave decomposition of particular schemes widely used is:

First order explicit upwind scheme (Burguete and García-Navarro 2004a):

$$
\mathbf{G}_{i+(1 / 2)}^{L}=\left(\boldsymbol{\Omega}^{+} \mathbf{G}\right)_{i+(1 / 2)}^{n}, \quad \mathbf{G}_{i+(1 / 2)}^{R}=\left(\boldsymbol{\Omega}^{-} \mathbf{G}\right)_{i+(1 / 2)}^{n}
$$

First order upwind implicit (Burguete and García-Navarro 2004b):

$$
\mathbf{G}_{i+(1 / 2)}^{L}=\left\{\boldsymbol{\Omega}^{+}\left[\mathbf{G}-\theta \frac{\delta(\mathbf{J} \Delta \mathbf{u})}{\delta x}\right]\right\}_{i+(1 / 2)}^{n}, \quad \mathbf{G}_{i+(1 / 2)}^{R}=\left\{\boldsymbol{\Omega}^{-}\left[\mathbf{G}-\theta \frac{\delta(\mathbf{J} \Delta \mathbf{u})}{\delta x}\right]\right\}_{i+(1 / 2)}^{n}
$$

Lax-Wendroff (Burguete and García-Navarro 2004a):

$$
\mathbf{G}_{i+(1 / 2)}^{L}=\frac{1}{2}\left(1+\frac{\Delta t}{\delta x} \mathbf{J}_{i+(1 / 2)}^{n}\right) \mathbf{G}_{i+(1 / 2)}^{n}, \quad \mathbf{G}_{i+(1 / 2)}^{R}=\frac{1}{2}\left(1-\frac{\Delta t}{\delta x} \mathbf{J}_{i+(1 / 2)}^{n}\right) \mathbf{G}_{i+(1 / 2)}^{n}
$$

\section{Friction term related numerical stability conditions}

Explicit numerical schemes applied to solve the unsteady Saint-Venant equations are said to be numerically stable if the time step and grid size chosen are linked by the CFL condition (Courant et al. 1928) based on the advective character of the equations. The implementation of this condition in equation (1), with the flux Jacobian eigenvalues (6), gives:

$$
\mathrm{CFL}=\Delta t \frac{\beta|\bar{u}|+\sqrt{\left(\beta^{2}-\beta\right) \bar{u}^{2}+c^{2}}}{\delta x} \leq 1
$$

with CFL the dimensionless Courant-Friedrichs-Lewy number.

The friction source term in the Saint-Venant (1) equations is often one of the dominant terms, especially in river flow or surface irrigation applications, and it is essential to establish a stability condition that takes them into account. Despite earlier efforts in this direction, as (Liggett and Cunge 1977) for instance, the stability conditions of the Saint-Venant equations with important friction term have not been adequately addressed. One of the traditional approaches to analyze 
the stability of a numerical scheme is to study the amplification of the small perturbations that it produces. This analysis leads to some restrictions over the size of the time step (Liggett and Cunge 1977). The restrictions can be avoided using an implicit discretization of the friction term. However, in some practical cases of dominant friction neither the reduction of the time step size nor the implicit discretization of the friction term are enough to obtain stable solutions. This will be shown in a later section.

Three particular stability conditions will also be analyzed for the non-linear case. Even though they are not general, they can be useful to throw some light on the conditions that must be fulfilled in order to avoid instabilities due to the friction term.

\section{Stability with flat bottom and surface levels}

Assuming a rough, wide prismatic channel with initial flat bottom and surface levels $(R \approx H)$, and uniform initial discharge, the Saint-Venant equations can be simplified:

$$
\frac{\partial Q}{\partial t}=-T=-\frac{f Q^{2}}{8 H A}
$$

with the following solution:

$$
Q=\frac{8 H A Q_{0}}{8 H A+Q_{0} f t}
$$

so that the discharge solution decreases, tending to zero as the time increases to infinity. A first order upwind scheme will be applied to solve this problem. The numerical solution for the discharge at the $i$-th node is:

$$
Q_{i}^{n+1}=Q_{i}^{n}-\Delta t T_{i}^{n}=Q_{i}^{n}-\Delta t \frac{f}{8 H A}\left|Q_{i}^{n}\right| Q_{i}^{n}=\left(1-\Delta t \frac{f}{8 H A}\left|Q_{i}^{n}\right|\right) Q_{i}^{n}
$$

For the scheme to be stable the following must hold:

$$
\left|Q_{i}^{n+1}\right| \leq\left|Q_{i}^{n}\right|
$$

which is true for (52) provided that:

$$
\Delta t \frac{f}{8 H A}\left|Q_{i}^{n}\right| \leq 2
$$


If, on the other hand, we seek a solution free from oscillations, it must be observed that:

$$
0 \leq Q_{i}^{n+1} \leq Q_{i}^{n}
$$

which is a more restrictive solution hold by (52) when:

$$
\Delta t \frac{f}{8 H A}\left|Q_{i}^{n}\right| \leq 1
$$

This condition was proposed in (Liggett and Cunge 1977). Note that, contrary to the standard Courant-Friedrichs-Lewy condition (49), the present stability condition restricts the time step size independently of the spatial step. Thus, instabilities due to the friction term are most likely in coarse grids.

The stability conditions (54) and (56) disappear when using an implicit discretization of the source term. In that case, the numerical solution for the discharge at the $i$-th node is:

$$
Q_{i}^{n+1}=Q_{i}^{n}-\Delta t T_{i}^{n+1}=Q_{i}^{n}-\Delta t \frac{f}{8 H A}\left|Q_{i}^{n+1}\right| Q_{i}^{n+1}
$$

hence:

$$
\left(1+\Delta t \frac{f}{8 H A}\left|Q_{i}^{n+1}\right|\right) Q_{i}^{n+1}=Q_{i}^{n}
$$

and the solution is stable and free from oscillations (55) since:

$$
1+\Delta t \frac{f}{8 H A}\left|Q_{i}^{n+1}\right| \geq 1 \Rightarrow 0 \leq Q_{i}^{n+1} \leq Q_{i}^{n}
$$

Therefore, the implicit treatment of the friction term is recommended if a coarse mesh is used in the presence of large roughness.

\section{Stability in adverse slope}

Assuming now a domain as sketched in Figure 4, a flat surface level develops over an adverse slope. In this situation, the momentum equation reduces to:

$$
\frac{\partial Q}{\partial t}+\frac{\partial}{\partial x}\left(\frac{Q^{2}}{A}\right)=-T
$$

Let us call $i$ the grid node where the wet/dry front is located. The following is expected at that point:

$$
Q_{i}^{n}=A_{i}^{n}=0, \quad Q_{i-1}^{n} \geq 0, \quad A_{i-1}^{n} \geq 0, \quad Q_{i}^{n+1} \geq 0, \quad A_{i}^{n+1} \geq 0
$$


Taking into account (60), the following can be written for a conservative numerical scheme:

$$
Q_{i}^{n+1}=Q_{i}^{n}-\Delta t\left[T+\frac{\delta}{\delta x}\left(\frac{Q^{2}}{A}\right)\right]_{i-(1 / 2)}^{L}
$$

The most common way is to perform the arithmetic mean:

$$
T_{i-(1 / 2)}^{n}=\frac{T_{i-1}^{n}+T_{i}^{n}}{2}=\frac{T_{i-1}^{n}}{2}
$$

In order to enforce the physical condition (61) an explicit numerical scheme must satisfy:

$$
\frac{T_{i-1}^{n}}{2} \delta x-\frac{\left(Q_{i-1}^{n}\right)^{2}}{A_{i-1}^{n}} \leq 0
$$

Using this equation and the friction models (12) or (9) in (64) the following condition is found:

$$
\delta x \leq \frac{16 R}{f}=\frac{2 R^{\frac{4}{3}}}{g n^{2}}
$$

The result of this discussion is that the grid size appears to be limited by the hydraulic radius and the roughness in order to enforce stability on the numerical solution. Furthermore, it is easy to show that always, when the CFL condition holds, this condition is stronger than the time step restriction (54) and, for subcritical flow, stronger than (56).

\section{Stability in wet/dry advancing fronts}

In the particular situation of a wave front advancing over a dry sloping channel, the momentum equation is:

$$
\frac{\partial Q}{\partial t}+\frac{\partial}{\partial x}\left(g I_{1}+\frac{Q^{2}}{A}\right)=-T+g A S_{0}
$$

For $i$, the grid node where the wet/dry front is located, (61) is expected at that point. Taking into account (66), the following can be written for a conservative numerical scheme:

$$
Q_{i}^{n+1}=Q_{i}^{n}-\Delta t\left[T-g A S_{0}+\frac{\delta}{\delta x}\left(g I_{1}+\frac{Q^{2}}{A}\right)\right]_{i-(1 / 2)}^{L}
$$

using the arithmetic mean, in order to enforce the physical condition (61) an explicit numerical scheme must satisfy:

$$
\frac{1}{2} T_{i-1}^{n} \delta x \leq \frac{1}{2}\left(g A S_{0}\right)_{i-1}^{n} \delta x+g\left(I_{1}\right)_{i-1}^{n}+\frac{\left(Q_{i-1}^{n}\right)^{2}}{A_{i-1}^{n}}
$$


this condition is always true for sloping beds provided that (64):

$$
T_{i-1}^{n} \delta x \leq \frac{2\left(Q_{i-1}^{n}\right)^{2}}{A_{i-1}^{n}} \leq\left(g A S_{0}\right)_{i-1}^{n} \delta x+2 g\left(I_{1}\right)_{i-1}^{n}+\frac{2\left(Q_{i-1}^{n}\right)^{2}}{A_{i-1}^{n}}
$$

Therefore, although deduced from a particular case, (64) is a sufficient practical rule to obtain stable solutions in problems of wetting fronts over dry beds.

\section{Validation and applications}

When a set of $N$ measured velocity data is available at a given cross section, $\beta$ can be estimated as follows:

$$
\beta=\frac{A \int_{A} u^{2} d A}{\left(\int_{A} u d A\right)^{2}} \approx \frac{A \sum_{i=1}^{N} u_{i}^{2} A / N}{\left(\sum_{i=1}^{N} u_{i} A / N\right)^{2}}=\frac{N \sum_{i=1}^{N} u_{i}^{2}}{\left(\sum_{i=1}^{N} u_{i}\right)^{2}}
$$

where it must be noted that the velocity value is considered uniform in a region of size $A / N$ around the measurement point. Therefore, the estimation is better when a greater number of points is used and also when they are more uniformly distributed. However, as the velocity in those regions will be non-uniform in many cases, this approach tends, in general, to underestimate $\beta$.

\section{Compound section laboratory channel}

In order to validate some of the friction models proposed in this paper a laboratory experiment has been set up. A flat bottom $\left(S_{0} \approx 0\right), 6 \mathrm{~m}$ long smooth channel of compound cross section as represented in Figure 5 was used. The channel was fed with a constant discharge and water depth was measured at a location $4.63 \mathrm{~m}$ from the channel inlet to ensure fully developed flow. The outlet was supplied with a device to separate the main channel and flood plain discharges. These were measured using a volumetric procedure. In this situation, according to (35) and (25), the presented models for compound section predict a ratio of flow velocity in the floodplain subsection $\left(U_{1}\right)$ to the flow velocity in the main subsection $\left(U_{2}\right)$ :

- CFS/MLE models: $U_{1} / U_{2}=\left(h_{1} / h_{2}\right)^{b+(1 / 2)}$ 
- MTFS model: $U_{1} / U_{2}=\left(h_{1} / h_{2}\right)^{2 b+1}$

Figure 6 shows the results obtained from the evaluations performed using 7 different discharges. In (a) the ratio of velocities has been plotted versus the ratio of water depths at the two subsections. In (b) the $\beta$ coefficient has been plotted versus the maximum depth. The estimations from experimental date are compared with the predictions from the CFS/MLE and MTFS models both using the $b$ exponents provided by Prandtl (17) and Gauckler-Manning equivalence (18). The MTFS model gives lower values of velocity and higher $\beta$ values in these cases. These cases do not provide experimental evidences of the superiority of extrem model.

\section{Experimental FCF series}

The experimental data from 50 cases measured in five smooth compound channel laboratory setups from the FCF series of the University of Birmingham (Knight 2004) have been used as additional validation. Figure 7 is a sketch of the channel cross section geometry. Figure 8 displays all the vertical velocity profiles, comparing the regression obtained using the experimental velocity data with the profiles corresponding to the Prandtl and Gauckler-Manning models. The plots show that both models provide a good approximation of the experimental vertical profiles.

Defining $U_{H}$ as the depth averaged velocity at the canal axis, the models predict the following relationships:

- CFS/MLE models: $U / U_{H}=(h / H)^{b+(1 / 2)}$

- MTFS model: $U / U_{H}=(h / H)^{2 b+1}$

Figure 9 is a plot of $U / U_{H}$ versus $h / H$ for all the cases. It shows that the CFS/MLE models fit reasonably well the measured profiles so that the regression from experimental data provides a curve similar to the one predicted by these models. Figures 10-12 are plots of $U$ versus $y$ for a few cases. The velocity values predicted by the CFS/MLE models agree with the observed values within a $20 \%$ of error. Finally, Figure 13 displays the variation of $\beta$ with $H$ both as predicted by the models and as estimated from the measurements according to (70). Again, the CFS/MLE models provide a 
closer prediction. The estimates of the MTFS model are far from the experimental estimation with a tendency to overpredict the value of $\beta$.

\section{Experimental river flow velocity data}

A set of more than 200 water velocity data, measured at a gauging station by the Statistics and Gauging Service of the Ebro River Water Authority (Confederación Hidrográfica del Ebro, Spain), have been used in the second case presented. The data were collected at an irregular section of the Ebro River by means of a probe located at different depths and transverse position within the section, under three different water discharge conditions $\left(26 \mathrm{~m}^{3} / \mathrm{s}, 68 \mathrm{~m}^{3} / \mathrm{s}\right.$ and $\left.147 \mathrm{~m}^{3} / \mathrm{s}\right)$. None of the discharges was extraordinary so that water was always in the main channel. The data were used to perform a linear regression so that the suitability of the considered friction models could be analyzed. The hypothesis made was that the bed river roughness is approximately the same all over the cross section. Figure 14 is a sketch of the location of the velocity measurement points for the three different discharges.

Figure 15 shows the regression obtained together with that from the Gauckler-Manning model in logarithmic scale. The velocity profile can be represented by a straight line but the regression coefficient is $b=0.27$. This is even a higher regression coefficient than $1 / 6$ derived from the GaucklerManning model, which suggests the revision of this model in natural rivers. On the other hand, it is interesting to note that the value obtained is rather close to 0.25 . With this value the power-law friction model is equivalent to the model recommended by Kellerhals (11) from gravel-bed rivers.

Figure 16 is a plot of $U / U_{H}$ versus $h / H$ for the three discharges. The MLE/CFS models fit better the velocity profiles, and, using the value $b=0.27$, the prediction is overlapped with the curve obtained by regression.

Figure 17 represents the comparison of the measured and predicted $U$ velocity values along the cross section for the three discharges. The MLE/CFS model prediction is closer to the experimental data.

Finally, Figure 18 displays the estimate of the $\beta$ value from the measured data as function of 
$H$ for the three discharges. It is compared with the predictions of this parameters provided by the models. Despite the good agreement of the velocity profiles supplied by the MLE/CFS models they slightly underestimate the value of $\beta$. This can be explained by the simplification made assuming that there is a uniform value of roughness coefficient in the cross section.

\section{Friction models in typical river cross sections}

The MLE/CFS model predictions of the $\beta$ values at four typical Ebro River cross sections will be next compared. The cross sections are represented in Figure 19. For the sake of this comparison, the value of the roughness coefficient is not relevant and a Gauckler-Manning number of $0.03 \mathrm{~s} \cdot \mathrm{m}^{-1 / 3}$, taken from the literature (Chow 1959), has been used.

Figure 20 shows the plot of the $\beta$ values predictions at the four river sections using different values of $b$. The value reached by this coefficient, as obtained with the proposed friction model, is close to 2 in some cases, indicating that the basic approximation of this coefficient by 1 is not realistic and can lead to inaccurate models. Having stated the acceptable validity of the model predictions under laboratory conditions, this is a good example that provides an evidence of the values of $\beta$ in realistic conditions.

\section{Experiments on an impervious irrigation border}

The experimental data from (García-Navarro et al. 2000) were used to validate the proposed friction models in cases of steady and unsteady flow in conditions of high relative roughness. In that experiment a free-draining irrigation border $200 \mathrm{~m}$ long and $2 \mathrm{~m}$ wide, with a slope of $S_{0}=0.000671$ was constructed and covered with plastic film. A fine layer gravel (with $d_{50}$ of approximately $10 \mathrm{~mm}$ ) was added on top of the plastic film. A steady flow case was measured for a discharge of $Q=0.010$

$\mathrm{m}^{3} / \mathrm{s}$. Two unsteady experiments of water flow advancing over the dry border bed were performed using inlet discharges of $Q=0.0047 \mathrm{~m}^{3} / \mathrm{s}$ and $Q=0.0117 \mathrm{~m}^{3} / \mathrm{s}$. For the numerical simulation of the unsteady flow, agrid with $\delta x=0.2 \mathrm{~m}$ and a first order upwind scheme with implicit source term discretization was used. 
As a first approach, considering the size of the gravel, a characteristic roughness length of $l=$ $d_{50}=10 \mathrm{~mm}$ was used. According to this, the values of $n=0.019 \mathrm{~s} \cdot \mathrm{m}^{-1 / 3}$ and $\epsilon=0.012$ from the Strickler estimations (19) and (21) were be applied.

Furthermore, a second approach was based on an estimation of the roughness coefficients from normal flow conditions at steady state. Using the experimental steady flow depth of $H=50 \mathrm{~mm}$, the resulting Gauckler-Manning $n$ was $0.035 \mathrm{~s} \cdot \mathrm{m}^{-1 / 3}$ and, for $b=1 / 6$, the adjustment of the $\epsilon$ parameter resulted in a value of 0.040. It must be noted that these values are larger than those predicted by the Strickler law.

Figure (21) shows the comparison of the measured and the computed advancing fronts. The curves labelled with IV correspond to the Gauckler-Manning model with $n=0.019 \mathrm{~s} \cdot \mathrm{m}^{-1 / 3}$ and the curves labelled with II correspond to the power-law model with $\epsilon=0.012$, both derived from the Strickler law. Although the power-law model provides a better approach, both simulated advances are faster than the experimental, indicating that the actual roughness is underpredicted by this law in cases of high relative roughness. The curves labelled with III correspond to the Gauckler-Manning with $n=0.035 \mathrm{~s} \cdot \mathrm{m}^{-1 / 3}$, calibrated in the normal steady state. This curve shows that the steady state roughness coefficient leads to a too fast advance again. The curves labelled with I correspond to the power-law model with $\epsilon=0.040$ calibrated at steady state. The best agreement of the curves I with the experimental advance curve is noticeable. This justifies the convenience of using the correction $\left[1-(l / h)^{1+b}\right]^{-2}$ introduced by the power-law model in cases of high relative roughness.

Figure 22 illustrates the application of the stability condition (65). Only the case corresponding to the Gauckler-Manning model with $n=0.035 \mathrm{~s} \cdot \mathrm{m}^{-1 / 3}$ has been plotted for this analysis. In the experimental conditions, $(65)$ leads to the restriction $\delta x \leq \frac{2 \cdot 0.01^{4 / 3}}{9 \cdot 8 \cdot 0.035^{2}} \approx 0.4 \mathrm{~m}$. The values of discharges show the usual pattern in the form of a smooth advancing curve for $\delta x$ of 0.2 and $0.5 \mathrm{~m}$. Despite the implicit discretization of the source term, the simulation fails (the discharges become increasingly erratic) as $\delta x$ exceeds from $0.4 \mathrm{~m}$, thus confirming the relevance of the stability condition. 


\section{Conclusions}

This work has been mainly devoted to obtaining a deeper insight in the existing relation between friction models and vertical velocity profiles in one-dimensional shallow water formulations. From this relation, some velocity profile functions have been identified with the classical Gauckler-Manning or Kellerhals models. The velocity profiles obtained for smooth channels such as those in the Birmingham University FCF series, agree well with the predictions of the Gauckler-Manning model, however, regression coefficients taken at a river gauging station differ from the ones predicted by the Gauckler-Manning law, being in better agreement with the recommended by Kellerhals. Furthermore, a correction in cases of high relative roughness has been proposed. This is based on the existence of a sublayer in the flow next to the solid surface that can be considered at rest. This correction has provided a considerable improvement in the prediction of the advancing front in the case of flow over an impervious irrigation border.

In irregular or compound cross sections, two exremal hypotheses have been analysed for the cross sectional velocity distribution, one based on the minimization of the friction losses (MLE model) and another based on the minimization of total friction stress (MTFS model). The MLE model leads to results identical to the classical hypothesis of a constant friction slope across the wetted cross section (CFS model), thus reinforcing its physical ground and validity. The experimental validation has been helpful to show the agreement with the predictions of the MLE/CFS models. On the other hand, the results of the MTFS model are not so close to the experimental data. The cross sectional velocity distributions proposed can also be used to estimate the cross sectional momentum correction factor $\beta$. Our calculations show that this factor must be evaluated since it can reach values much higher than the usually assumed value of $\beta=1$ in cases of flood over a floodplain.

A new roughness-related numerical stability condition has been derived for unsteady shallow water flow simulations in presence of high relative roughness. It restricts the size of the spatial grid as a function of the water depth and the bed roughness. The stability condition has been tested in simulations of an experimental border. Results indicate that for low discharges in very rough beds it becomes necessary to restrict the spatial grid size below the prescribed limit in order to be able 
to obtain stable numerical solutions.

\section{Acknowledgements}

The flow velocity data measured by the Statistics and Gauging Service of the Ebro River Basin Water Authority (Confederación Hidrográfica del Ebro) have been very useful to validate the friction models analyzed in this work and are acknowledged.

\section{List of symbols}

The following symbols are used in this paper:

$B=$ wetted cross sectional top width;

$b=$ fitting velocity exponent;

$c=$ velocity of the infinitesimal waves;

$\mathrm{CFL}=$ dimensionless Courant-Friedrichs-Lewy number;

$d_{50}=$ bed particle size mean diameter;

$\mathbf{F}=$ conservative flux;

$f=$ Darcy-Weisbach friction factor;

$\mathbf{G}=$ updating term used in unified discretization;

$g=$ gravitational acceleration;

$H=$ maximum cross sectional depth;

$\mathbf{H}=$ source term;

$h=$ local water depth;

$I_{1}, I_{2}=$ pressure force integrals; 
$\mathbf{J}=$ flux Jacobian;

$\mathbf{K}=$ source term Jacobian;

$l=$ average size of the bed roughness irregularities (rough channels) or viscous sublayer thickness (smooth channels);

$n=$ Gauckler-Manning coefficient;

$P=$ wetted perimeter;

$\mathbf{P}=$ eigenvectors matrix;

$Q=$ discharge;

$R=$ hydraulic radius;

$r=$ Kellerhals roughness coefficient;

$S_{0}=$ main bed slope;

$S_{f}=$ friction slope;

$T=$ friction stress over the solid surface in the channel cross section;

$t=$ time;

$\mathbf{u}=$ conserved variable;

$U=$ depth-averaged water velocity;

$U_{H}=$ depth-averaged water velocity at the channel axis;

$u=$ local flow velocity;

$\bar{u}=$ cross sectional averaged flow velocity;

$u_{l}=$ water velocity at a distance $l$ of the bed;

$x=$ longitudinal coordinate; 
$y=$ transversal coordinate;

$z=$ vertical coordinate;

$z^{\prime}=$ local bottom level with reference to the minimum bottom level in a cross section;

$z^{\prime \prime}=$ vertical coordinate with reference to the minimum bottom level in a cross section;

$z_{b}=$ minimum bottom level in a cross section;

$z_{s}=$ water surface level;

$\beta=$ cross sectional momentum correction factor;

$\Gamma=$ cross sectional discharge factor;

$\gamma=$ cross subsectional discharge factor;

$\Delta=$ temporal finite increments;

$\delta=$ spatial finite increments;

$\epsilon=$ dynamic friction constant;

$\zeta=$ vertical distance to the bottom level;

$\eta=$ cross sectional velocity constant;

$\theta=$ implicitness parameter;

$\boldsymbol{\Lambda}=$ eigenvalues diagonal matrix;

$\lambda=$ eigenvalues of the flux Jacobian;

$\xi=$ cross subsectional momentum correction factor;

$\sigma=$ section width;

$\tau=$ friction stress;

$\Psi=$ cross sectional discharge factor; 
$\psi=$ cross subsectional discharge factor;

$\boldsymbol{\Omega}^{+}, \boldsymbol{\Omega}^{-}=$upwind matrices;

\section{References}

Bathurst, J.C., Li, R.M., and Simons, D.B. (1981). "Resistance equations for large-scale roughness". ASCE Journal of the Hydraulics Division, 107(12), 1593-1613.

Bettess, R., and White, W.R. (1987). Extremal hypotheses applied to river regime. In Sediment transport in gravel bed rivers, Thorne, C.R., Bathurst, J.C., and Hey, R.D. (eds). J. Wiley \& Sons. Chichester. 767-789.

Burguete, J., and García-Navarro, P. (2001). "Efficient construction of high-resolution TVD conservative schemes for equations with source terms: application to shallow-water flows". International Journal for Numerical Methods in Fluids, 37(2), 209-248.

Burguete, J., and García-Navarro, P. (2004a). "Improving simple explicit methods for unsteady open channel and river flow". International Journal for Numerical Methods in Fluids, 45(2), $125-156$.

Burguete, J., and García-Navarro, P. (2004b). "Implicit schemes with large time step for non-linear equations: application to river flow hydraulics". International Journal for Numerical Methods in Fluids, 46(6), 607-636.

Cao, Z., Meng, J., Pender, G., and Wallis, S. (2006). "Flow resistance and momentum flux in compound open channels". ASCE Journal of Hydraulic Engineering, 132(12), 1272-1282.

Chanson, H. (1999). The hydraulics of open channel flow. Arnold, London.

Chow, V.T. (1959). Open channel hydraulics. McGraw-Hill, New York.

Courant, R., Friedrichs, K.O., and Lewy, H. (1928). "Über die partiellen Differenzengleichungen der mathematischen Physik". Mathematische Annalen, 100(1), 32-74. 
Cunge, J.A., Holly, F.M. Jr., and Verwey A. (1980). Practical aspects of computational river hydraulics. Pitman, London.

Darcy, H.P.G. (1858). Recherches expérimentales relatives aux mouvements de l'eau dans les tuyaux. Mémoires Présentées à l'Académie des Sciences, Paris.

García-Navarro, P., Playán, E., and Zapata, N. (2000). "Solute transport modeling in overland flow applied to fertigation". ASCE Journal of Irrigation and Drainage Engineering, 126(1), $33-41$.

Gauckler, P.G. (1867). Études théoriques et pratiques sur l'écoulement et le mouvement des eaux. Comptes Rendues de l'Académie des Sciences, Paris.

Jarrett, R.D. (1984). "Hydraulics of high-gradient streams". ASCE Journal of Hydraulic Engineering, 110(11), 1519-1539.

Kellerhals, R. (1967). "Stable channels with gravel-paved beds". ASCE Journal of the Waterways and Harbors Division, 93(1), 63-84.

Knight, D.W. (2004). "FCF Series". Flow Database at the University of Birmingham. <www. flowdata.bham.ac.uk> (Jan. 22, 2007).

Knight, D.W. (2006). River flood hydraulics: validation issues in one-dimensional flood routing models. In River Basin Modelling for Flood Risk Mitigation, Knight, D.W., and Shamesildin, A.Y. (eds). Taylor \& Francis, London.

Liggett, J.A., and Cunge, J.A. (1977). Numerical methods of solution of the unsteady flow equations. In Unsteady Flow in Open Channels, Mahmood, K., and Yevjevich, V. (eds). Water Resources Publications, Colorado.

MacGahey, C., Samuels, P.G., and Knight, D.W. (2006). A practical approach to estimating the flow capacity of rivers - application and analysis. Proceedings of River Flow 2006, Taylor \& Francis, Lisboa. 
Manning, R. (1890). On the flow of water in open channels and pipes. Institution of Civil Engineers of Ireland.

Saint-Venant, A.J.C.B. de (1871). Théorie de mouvement non-permanent des eaux avec application aux crues de rivières et á l'introduction des marées dans leur lit. Comptes Rendues de l'Académie des Sciences, Paris.

Shiono, K., Muto, Y., Knight, D.W., and Hyde, A.F.L. (1999). "Energy losses due to secondary flow and turbulence in meandering channels with overbank flow". Journal of Hydraulic Research, $37(5), 641-664$.

Smart, G.M. (1999). "Turbulent velocity profiles and boundary shear in gravel-bed rivers". ASCE Journal of Hydraulic Engineering, 125(2), 106-116.

Smart, G.M., Duncan, M.J., and Walsh, J.M. (2002). "Relatively rough flow resistance equations". ASCE Journal of Hydraulic Engineering, 128(6), 568-578.

Strickler, A. (1923). Beiträge zur Frage der Geschwindigkeitsformel und der Rauhligkeitszahlen für Ströme, Kanäle und Geschlossene Leitungen. Mitt. des Eidgenössischen Amtes für Wasserwirtschaft: Bern, vol. 16.

White, F.M. (1991). Viscous fluid flow. McGraw-Hill, New York. 


\section{List of Figures}

1 Coordinates system in a cross section. . . . . . . . . . . . . . . . 31

2 Power function fitting the velocity profile. . . . . . . . . . . . . . . . . . 32

3 Decomposition of the cross section in simple trapezoidal elements. . . . . . . . . . . 33

4 Rough prismatic channel with adverse slope and flat surface level. . . . . . . . . . . 34

$5 \quad$ Compound cross section of the channel. . . . . . . . . . . . . . . . . . . . . 35

6 Comparison in a compound cross section channel of (a) the velocity ratio versus depth ratio predicted by models and measured, (b) the $\beta$ parameter estimated from measures

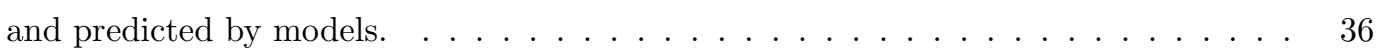

7 Cross section geometry of the FCF channels: (a) series I, (b) series II, (c) series III, (d) series VIII and (e) series X.

8 Comparison of the velocity ratio versus vertical coordinate ratio regressions and measurements in the FCF series channels. . . . . . . . . . . . . .

9 Dimensionless vertically averaged water velocity versus dimensionless water depth in the FCF series channels. Measurements and regressions. . . . . . . . . . . . . . . .

10 Depth-averaged water velocity measured and predicted by (a) CFS, (b) MTFS models with $b=0.12$ in the FCF channel series I. . . . . . . . . . . . . . . . . . . 40

11 Depth-averaged water velocity measured and predicted by (a) CFS, (b) MTFS models with $b=0.12$ in the FCF channel series II. . . . . . . . . . . . . . . . . . 41

12 Depth-averaged water velocity measured and predicted by (a) CFS, (b) MTFS models with $b=0.12$ in the FCF channel series III. . . . . . . . . . . . . . .

13 Comparison of the $\beta$ parameter versus depth as estimated from measures and predicted by models in the FCF channels: (a) series I, (b) series II, (c) series III, (d) series VIII and $(\mathrm{e})$ series $\mathrm{X} . \ldots \ldots \ldots \ldots \ldots \ldots$

14 Sketch of velocity measured points in the Ebro River cross section for discharges of (a) $147 \mathrm{~m}^{3} / \mathrm{s}$, (b) $68 \mathrm{~m}^{3} / \mathrm{s}$ and (c) $26 \mathrm{~m}^{3} / \mathrm{s} \ldots \ldots \ldots \ldots \ldots$ 
15 Comparison of the velocity ratio versus vertical coordinate ratio regressions and measurents in the Ebro River cross section. . . . . . . . . . . . . . . . . . . 45

16 Linear regression of the depth-averaged water velocity in terms of the water depth in the Ebro River cross section. . . . . . . . . . . . . . . . . . . . . 46

17 Depth-averaged water velocity measured and predicted by (a) MLE/CFS, (b) MTFS models with $b=0.27$ in the Ebro River cross section. . . . . . . . . . . . . . . . . 47

18 Comparison of $\beta$ coefficient versus depth estimated by measures and predicted by models in the Ebro River cross section. . . . . . . . . . . . . . . . . 48

19 Cross sectional form of four typical Ebro River sections. . . . . . . . . . . . . . . . 49

20 Values of the $\beta$ coefficient as a function of the water depth calculated using the MLE/CFS model with different $b$ values: (a) section I, (b) section II, (c) section III and $(\mathrm{d})$ section IV. . . . . . . . . . . . . . . . . . . . . 50

21 Advance curves with $\delta x=0.2 \mathrm{~m}$ and discharges of (a) $Q=0.0047 \mathrm{~m}^{3} / \mathrm{s}$ and (b) $Q=0.0117 \mathrm{~m}^{3} / \mathrm{s} \ldots \ldots \ldots \ldots \ldots \ldots \ldots \ldots$

22 Longitudinal discharge profiles corresponding to advancing time $t=1200 \mathrm{~s}$ with $Q=0.0047 \mathrm{~m}^{3} / \mathrm{s}$ and different values of $\delta x$. Gauckler-Manning model with $n=0.035$

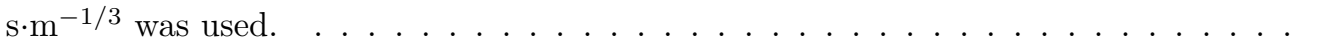


Figures

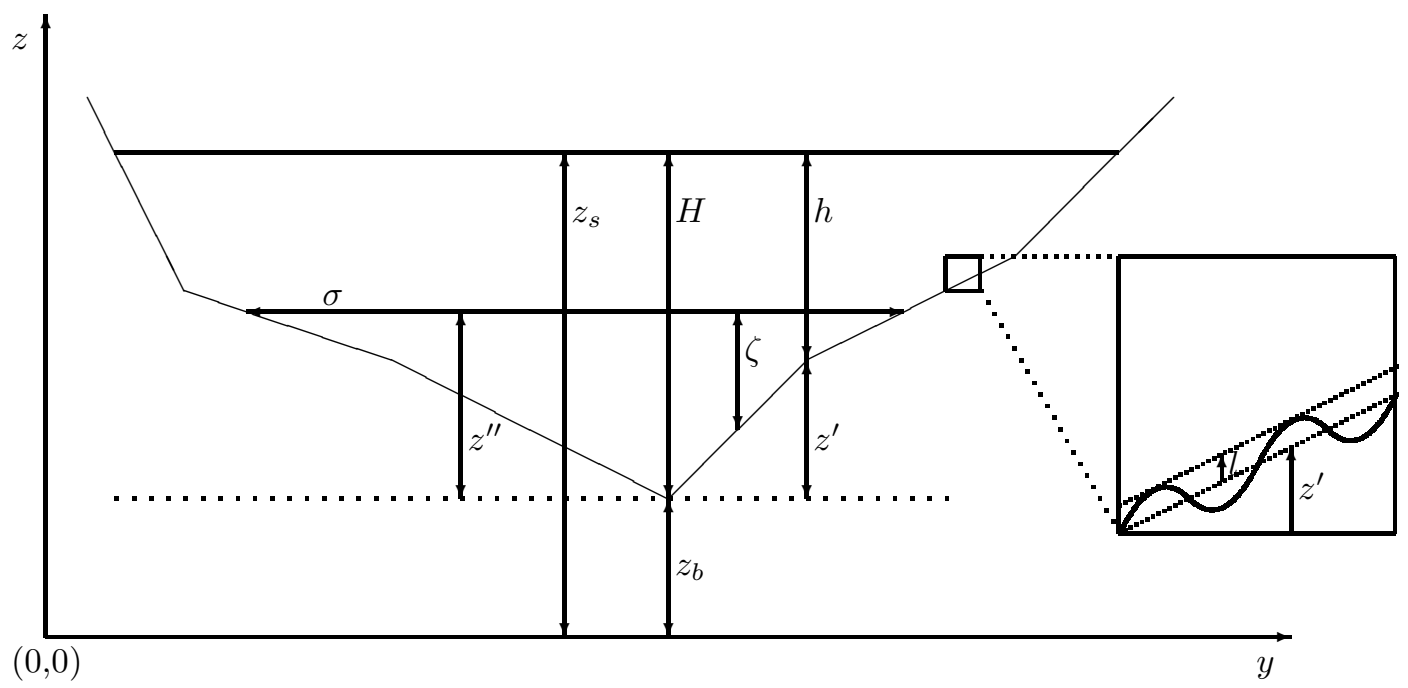

Figure 1: Coordinates system in a cross section. 


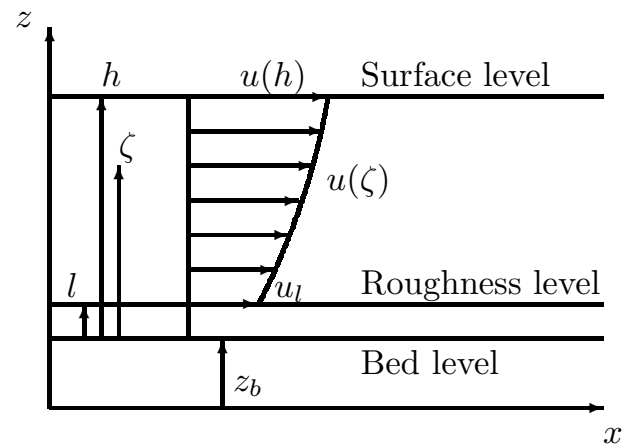

Figure 2: Power function fitting the velocity profile. 


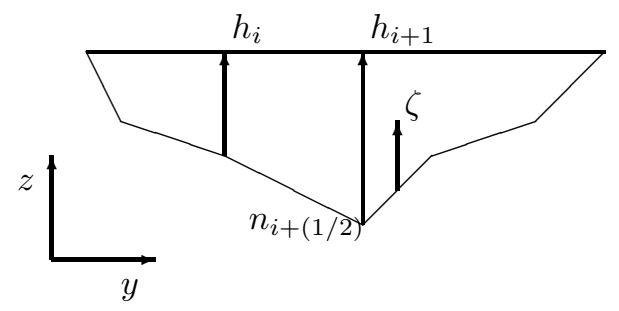

Figure 3: Decomposition of the cross section in simple trapezoidal elements. 


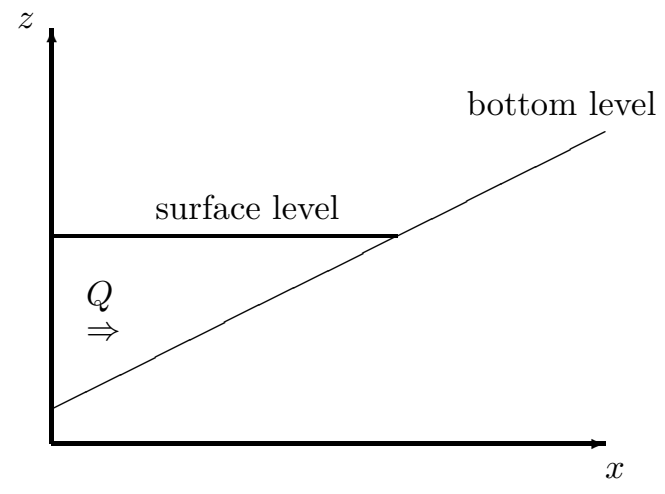

Figure 4: Rough prismatic channel with adverse slope and flat surface level. 


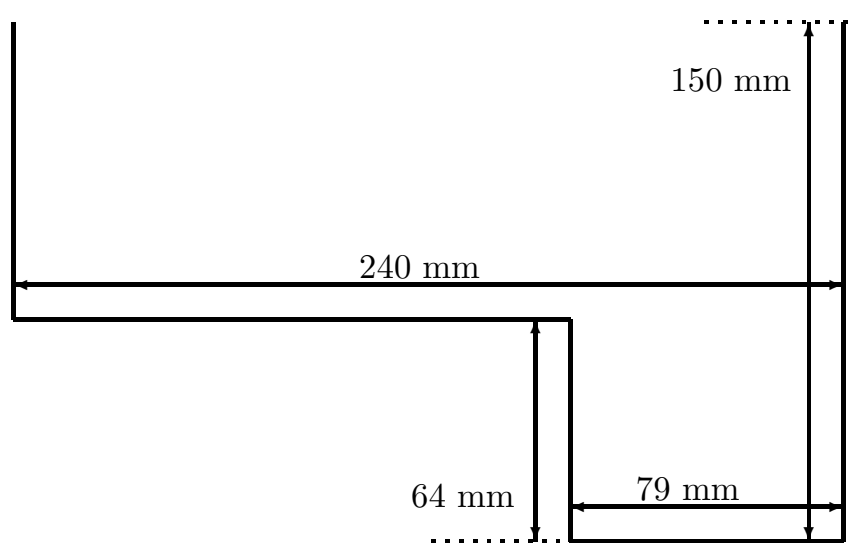

Figure 5: Compound cross section of the channel. 


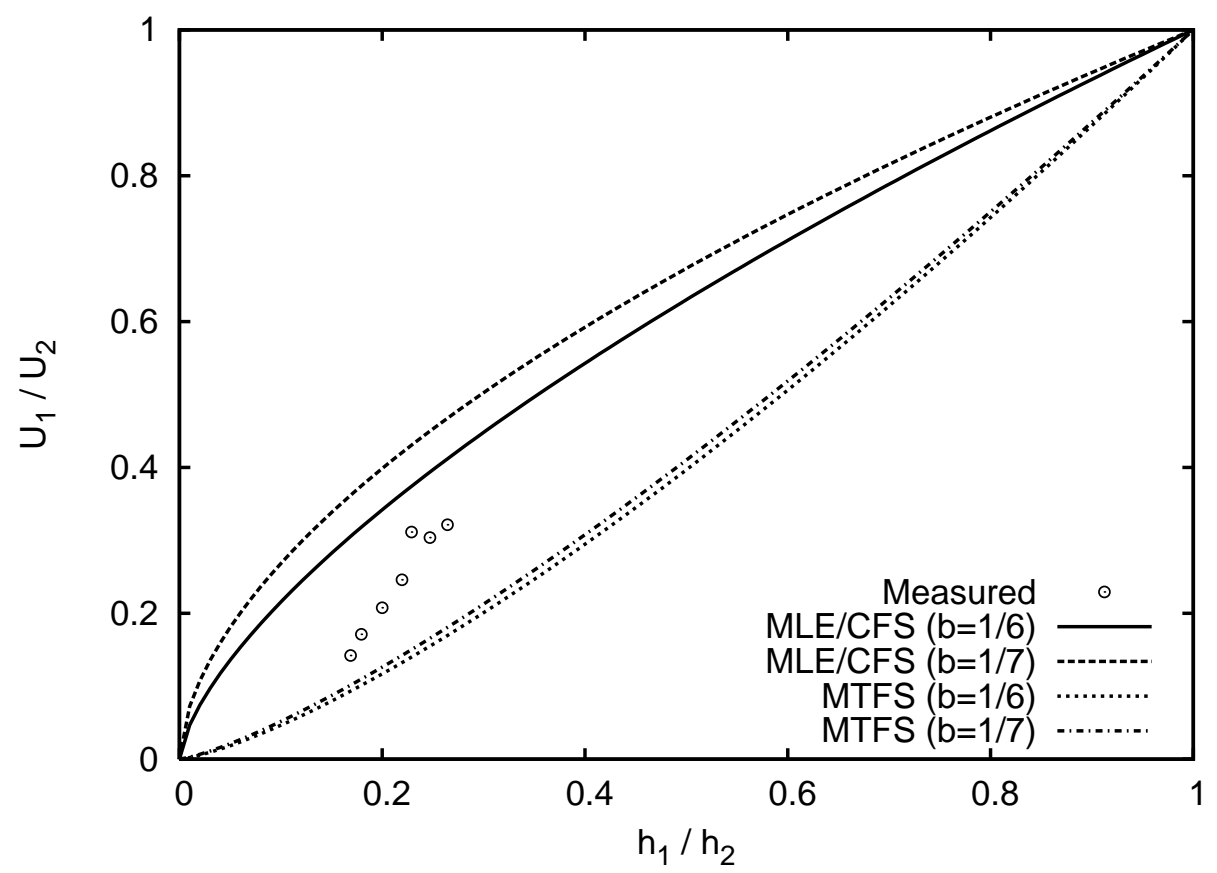

(a)

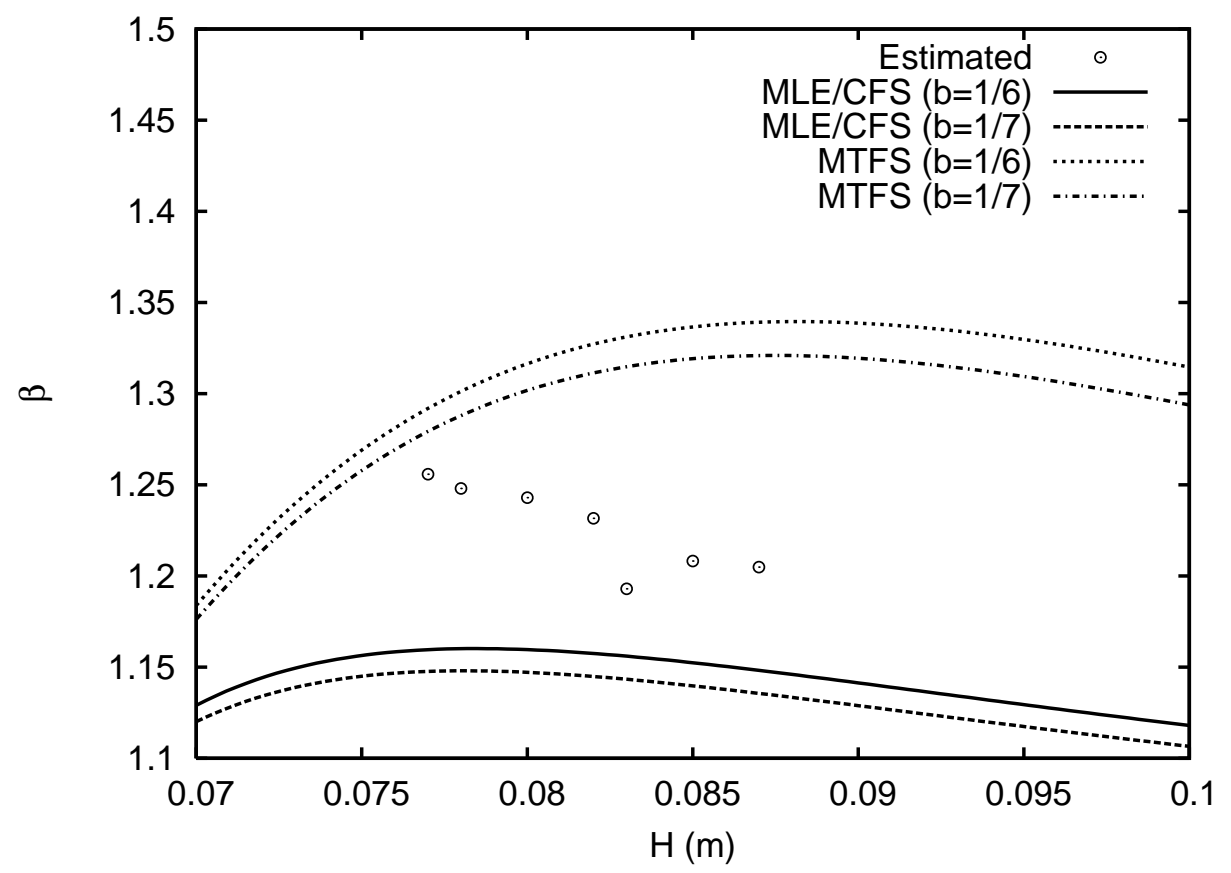

(b)

Figure 6: Comparison in a compound cross section channel of (a) the velocity ratio versus depth ratio predicted by models and measured, (b) the $\beta$ parameter estimated from measures and predicted by models. 


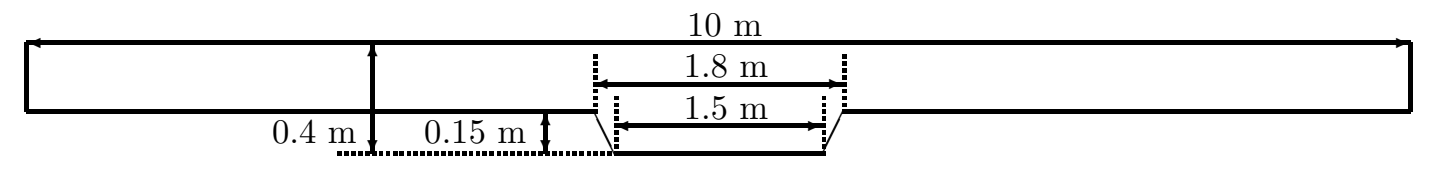

(a)

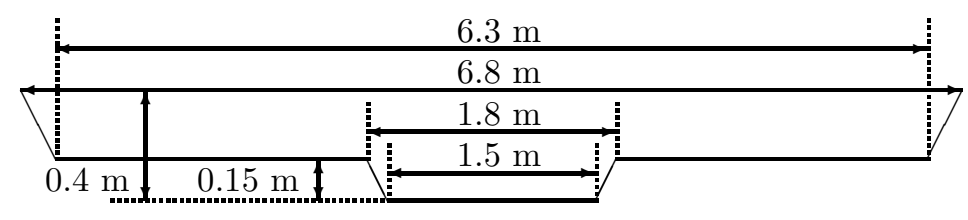

(b)

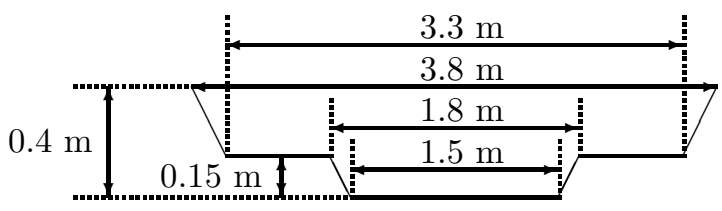

(c)

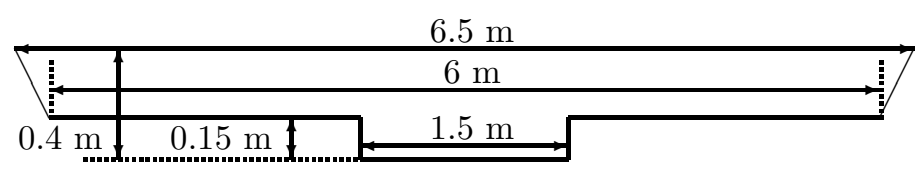

(d)

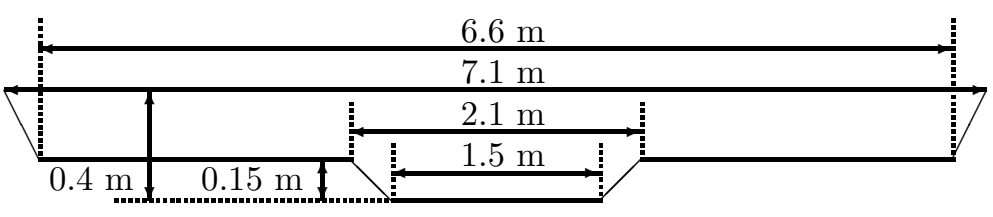

(e)

Figure 7: Cross section geometry of the FCF channels: (a) series I, (b) series II, (c) series III, (d) series VIII and (e) series X. 


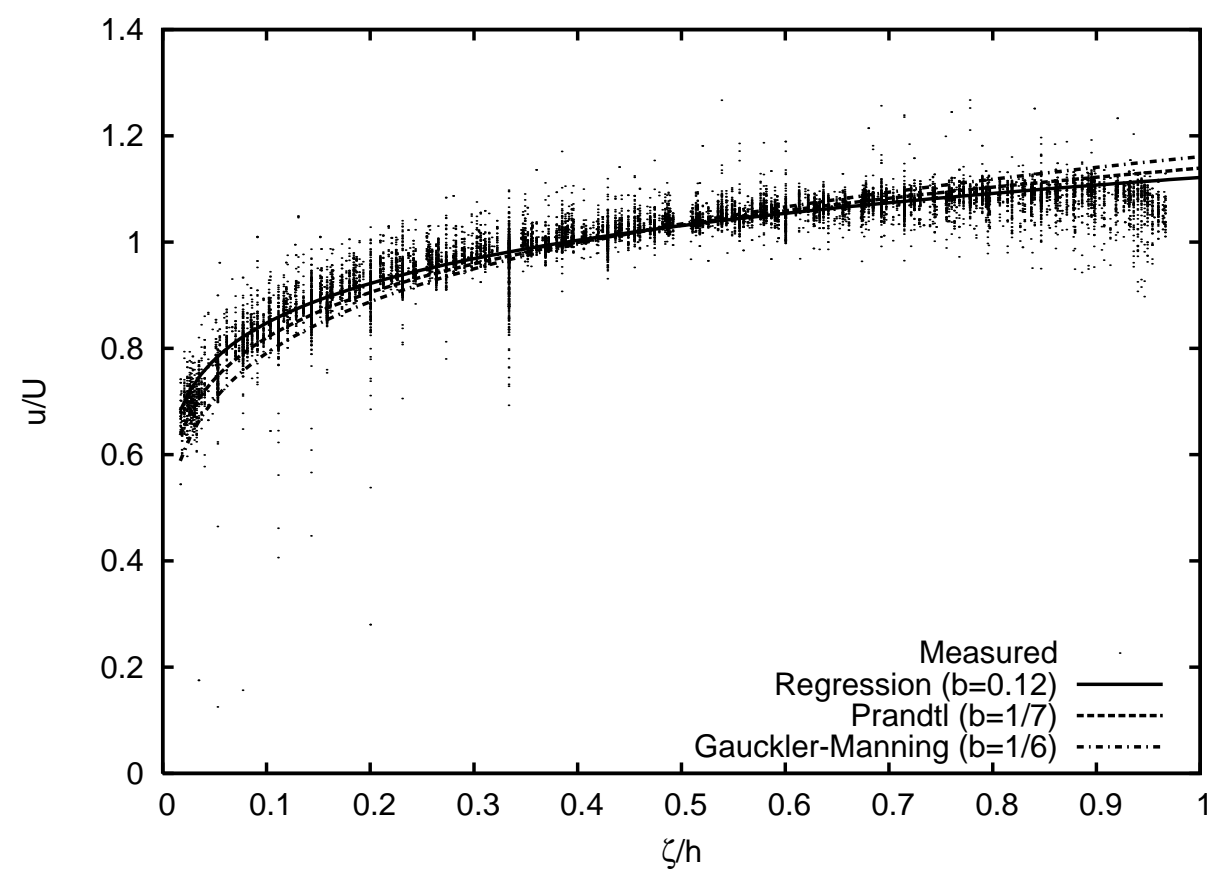

Figure 8: Comparison of the velocity ratio versus vertical coordinate ratio regressions and measurements in the FCF series channels. 


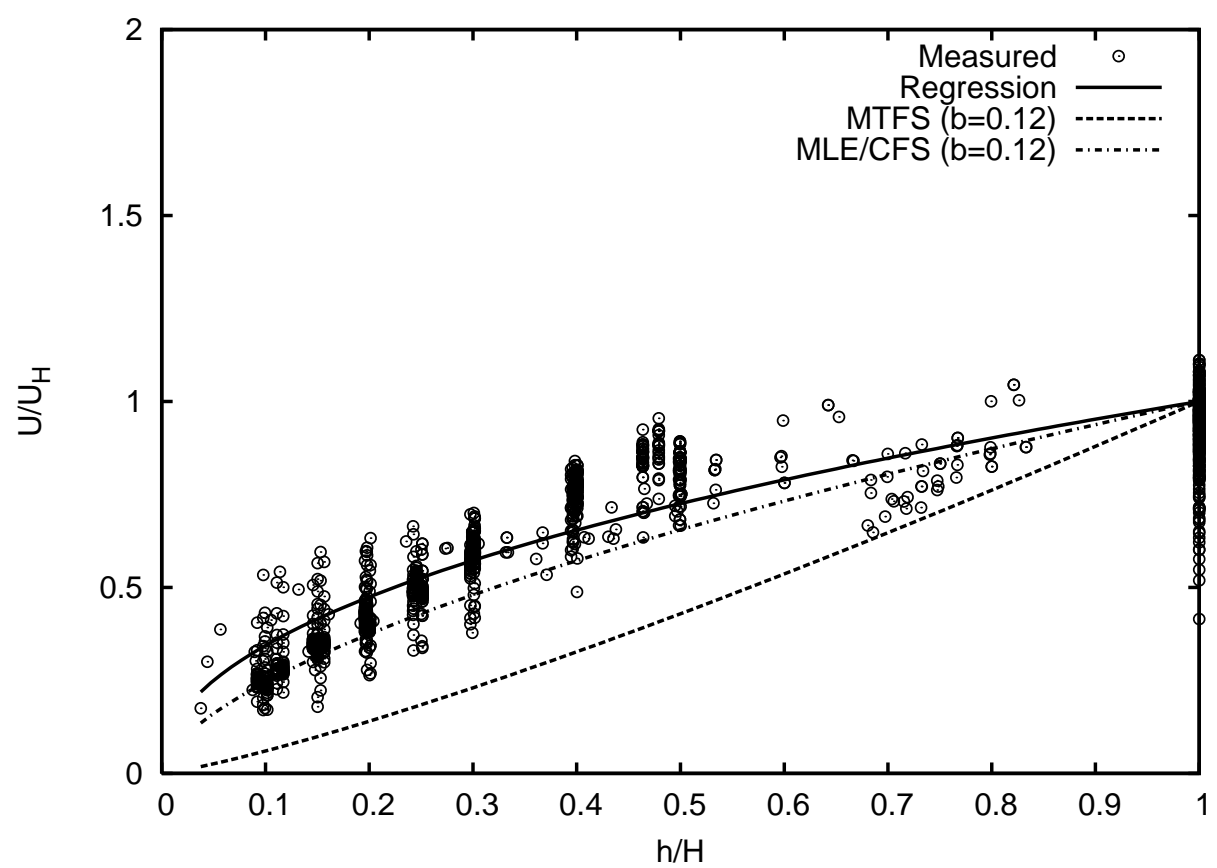

Figure 9: Dimensionless vertically averaged water velocity versus dimensionless water depth in the FCF series channels. Measurements and regressions. 


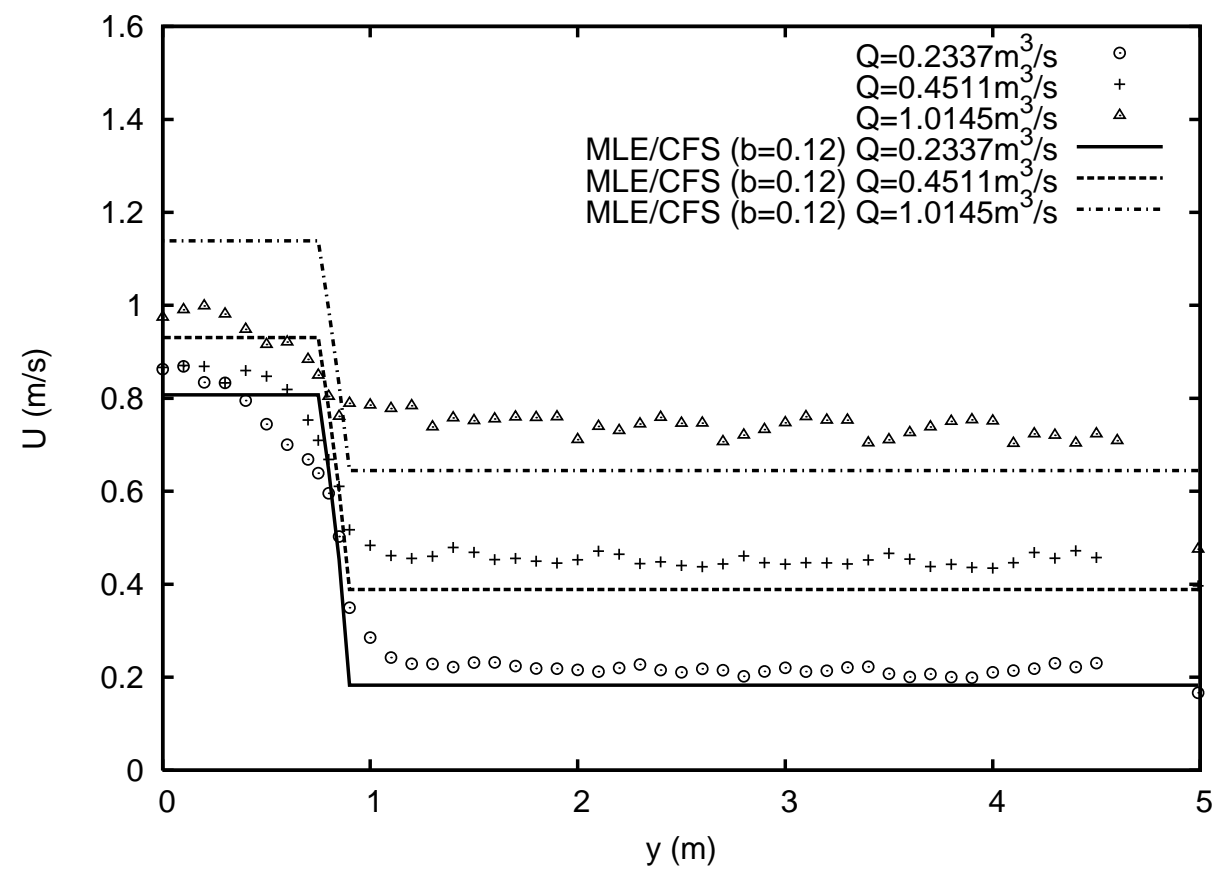

(a)

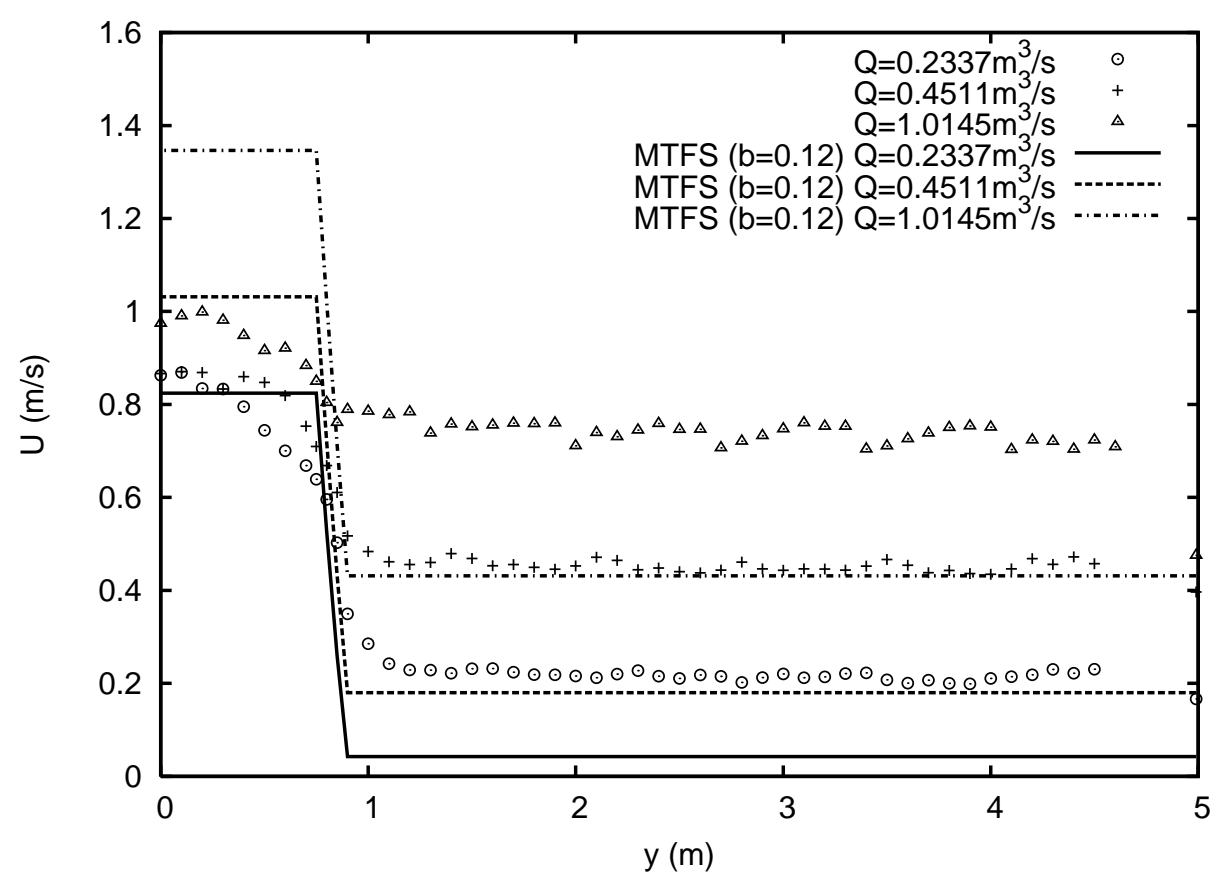

(b)

Figure 10: Depth-averaged water velocity measured and predicted by (a) CFS, (b) MTFS models with $b=0.12$ in the FCF channel series I. 


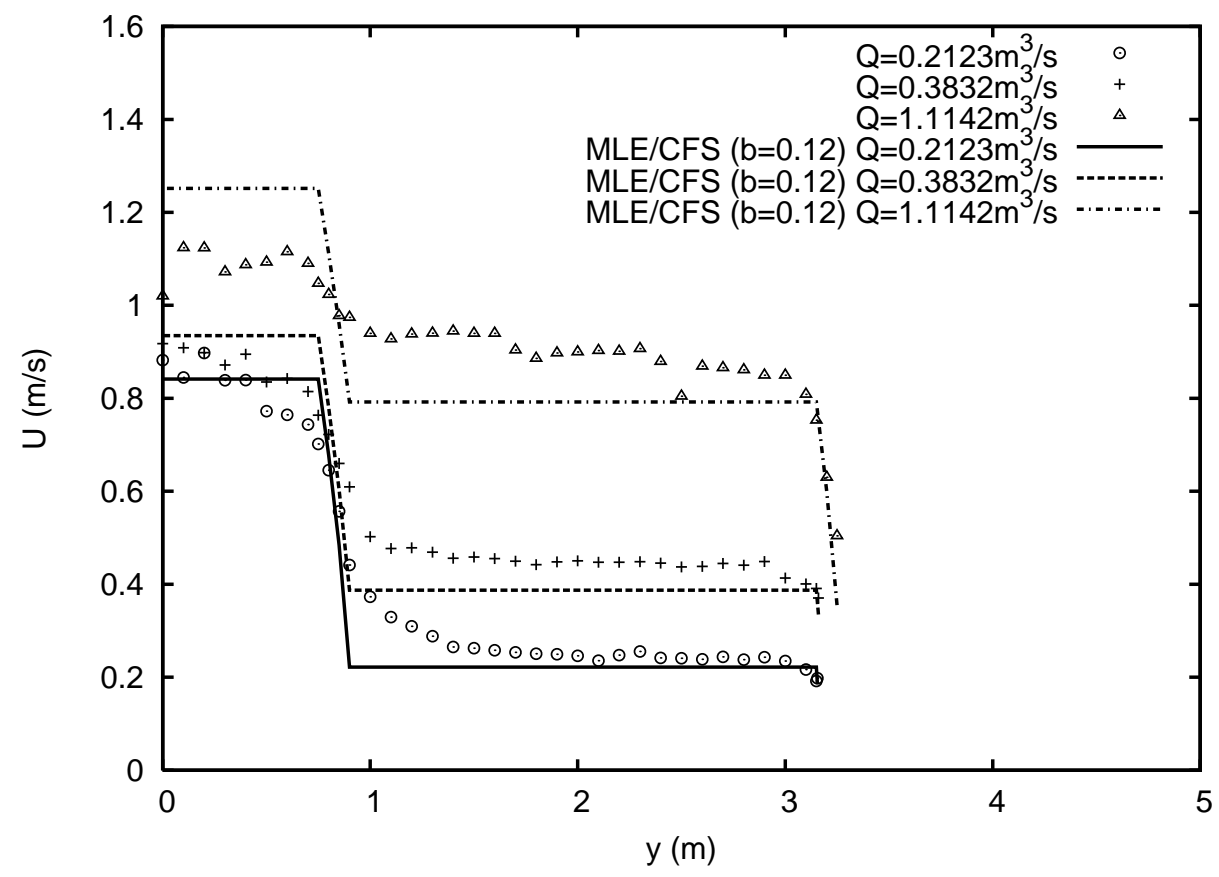

(a)

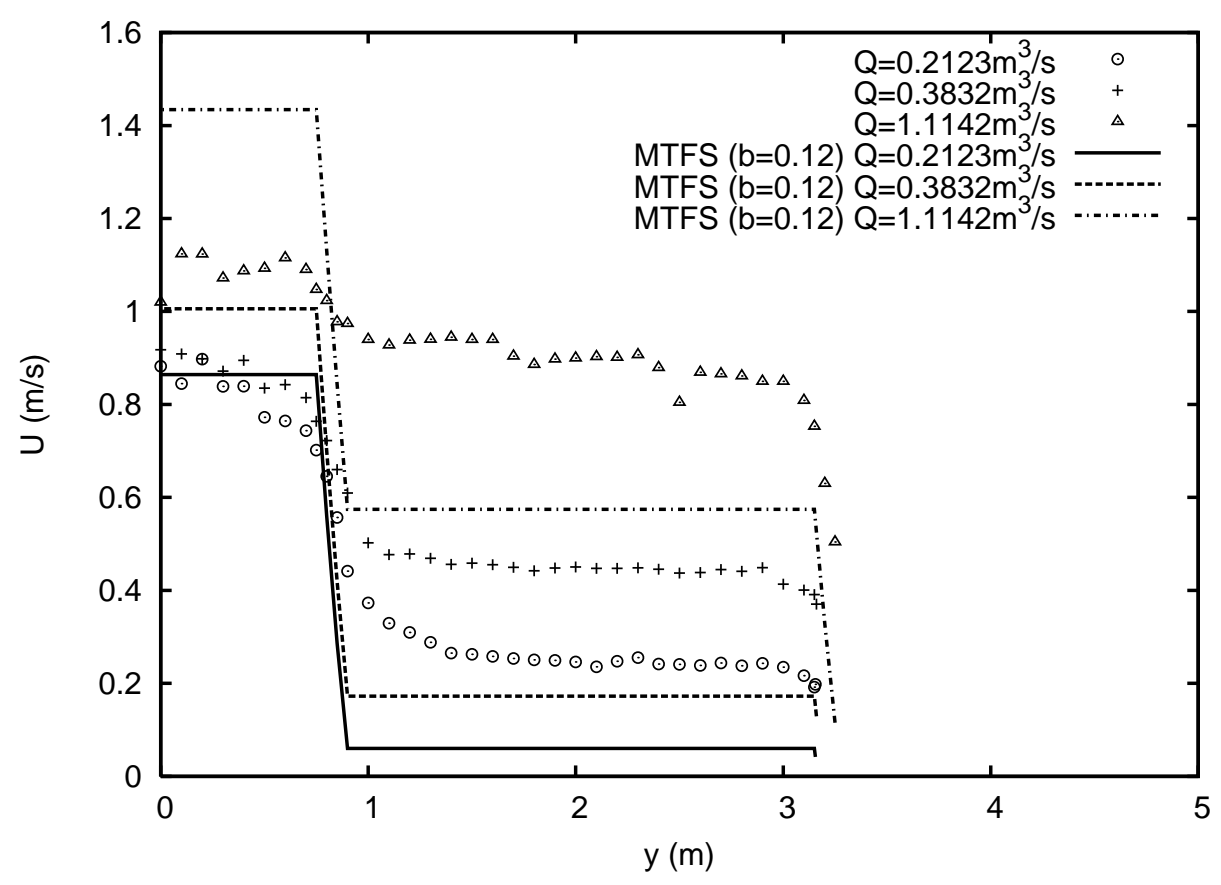

(b)

Figure 11: Depth-averaged water velocity measured and predicted by (a) CFS, (b) MTFS models with $b=0.12$ in the FCF channel series II. 


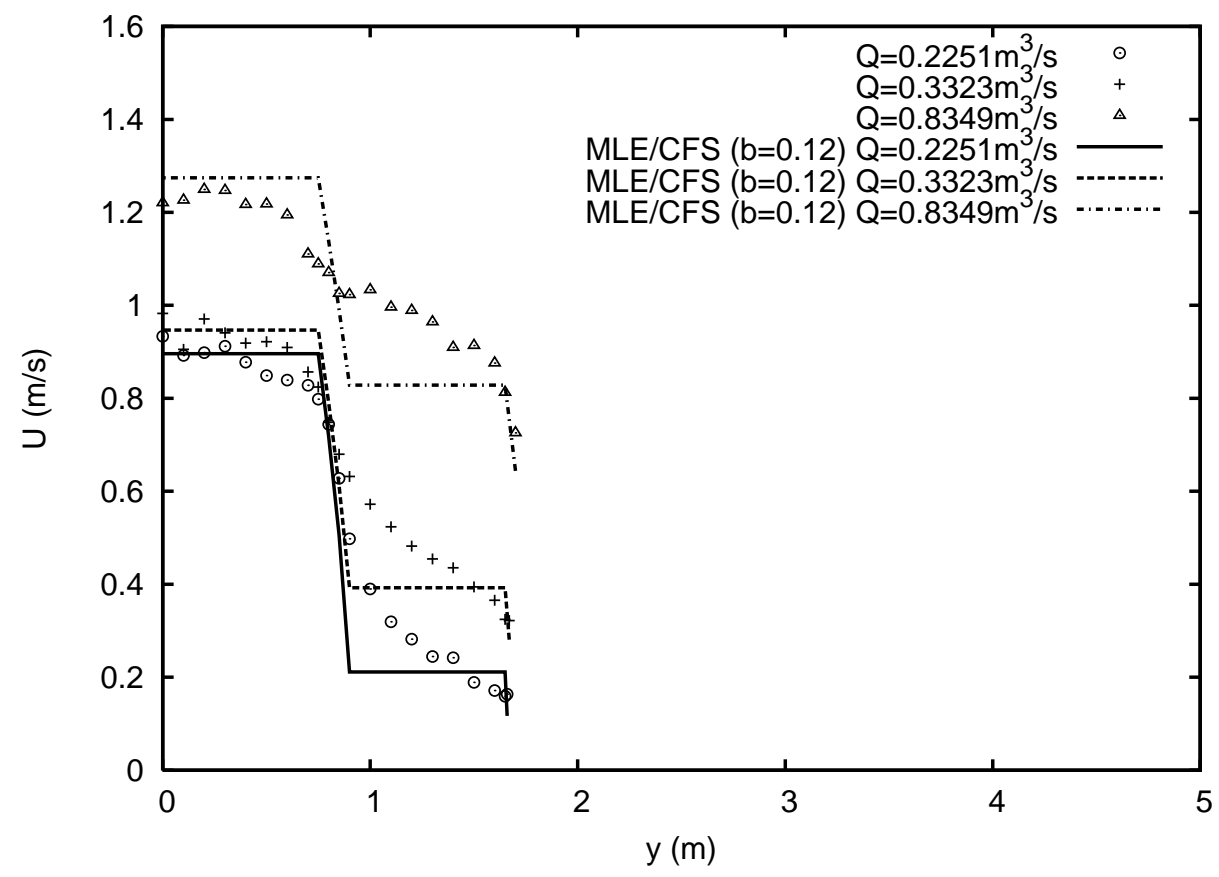

(a)

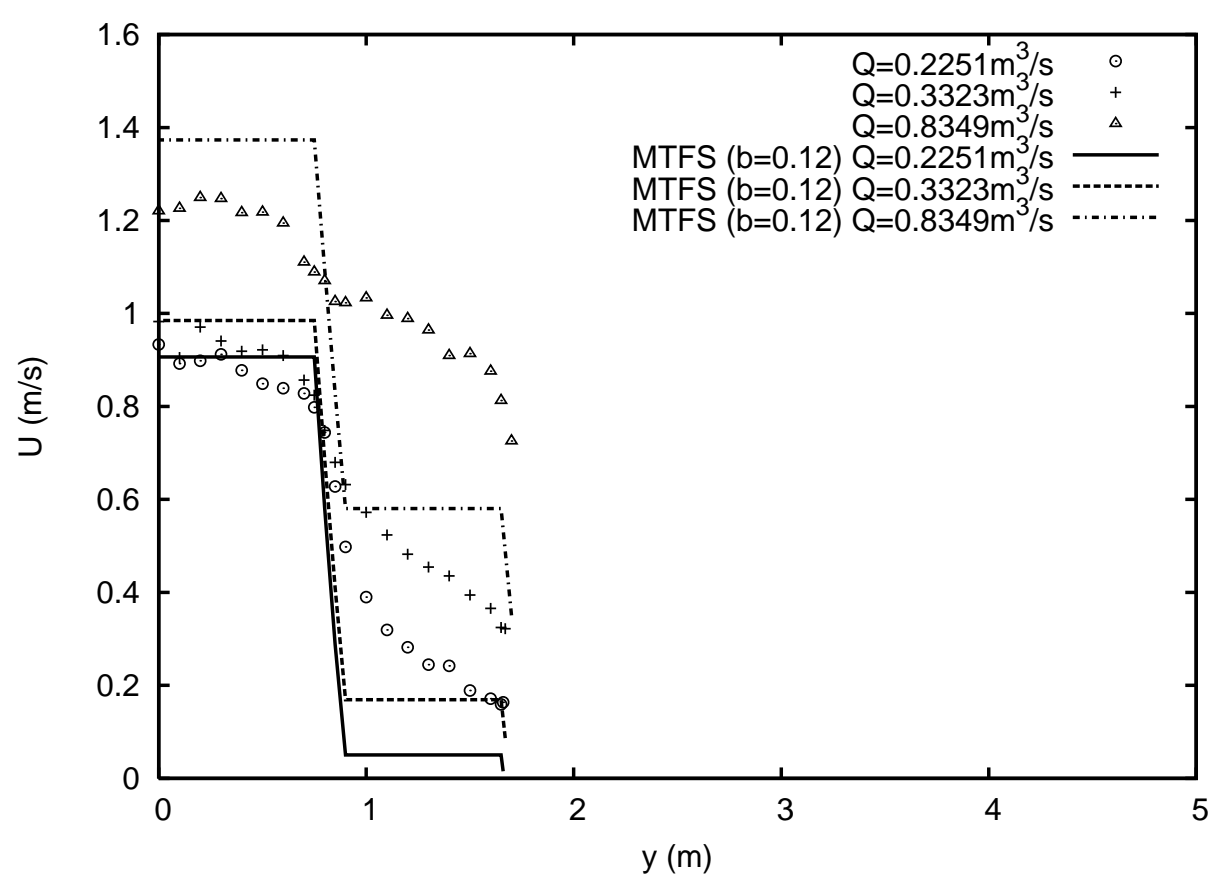

(b)

Figure 12: Depth-averaged water velocity measured and predicted by (a) CFS, (b) MTFS models with $b=0.12$ in the FCF channel series III. 


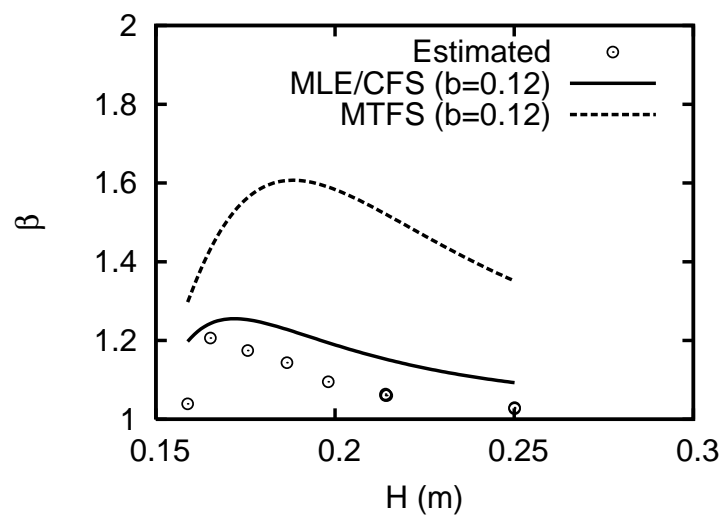

(a)

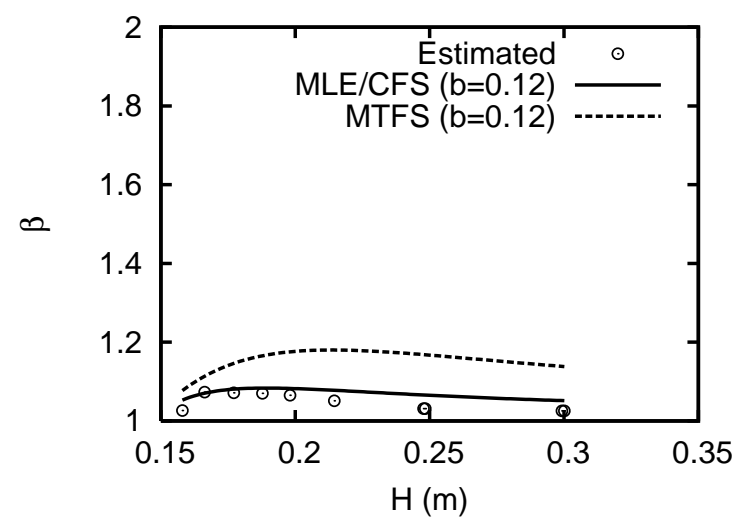

(c)

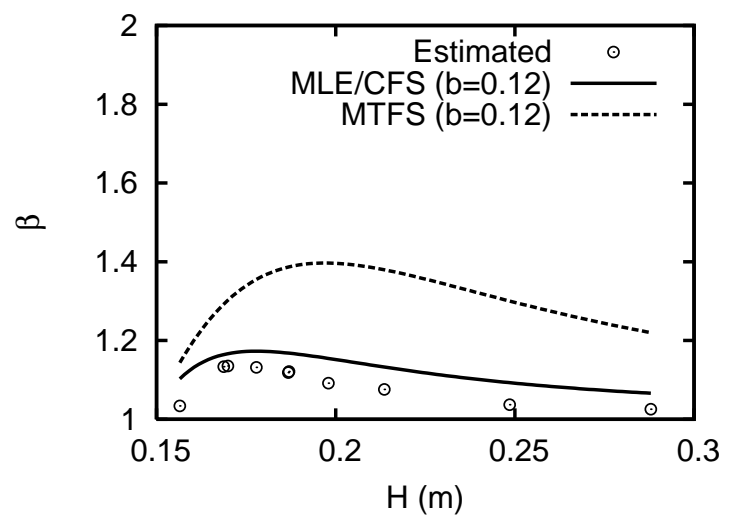

(b)

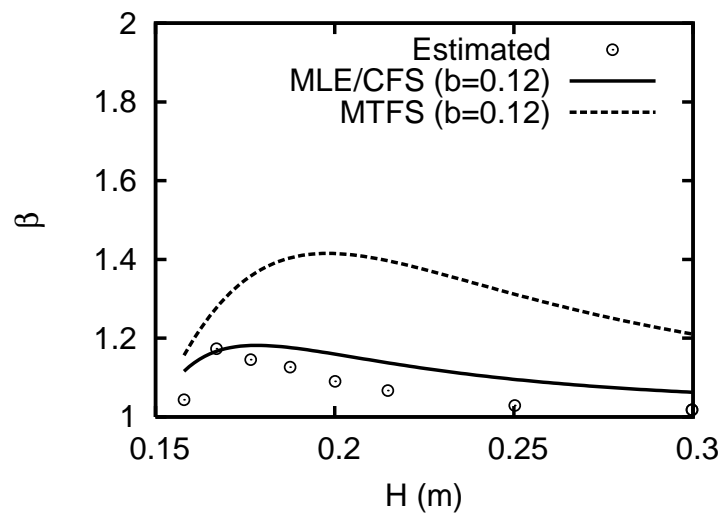

(d)

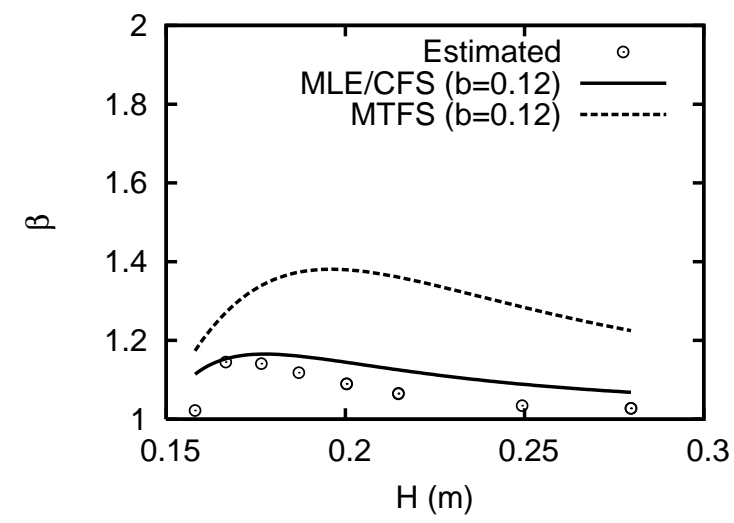

(e)

Figure 13: Comparison of the $\beta$ parameter versus depth as estimated from measures and predicted by models in the FCF channels: (a) series I, (b) series II, (c) series III, (d) series VIII and (e) series $\mathrm{X}$. 


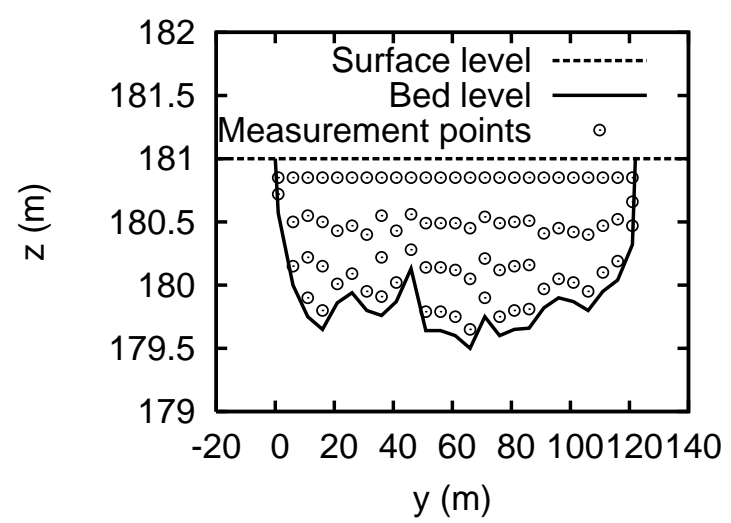

(a)

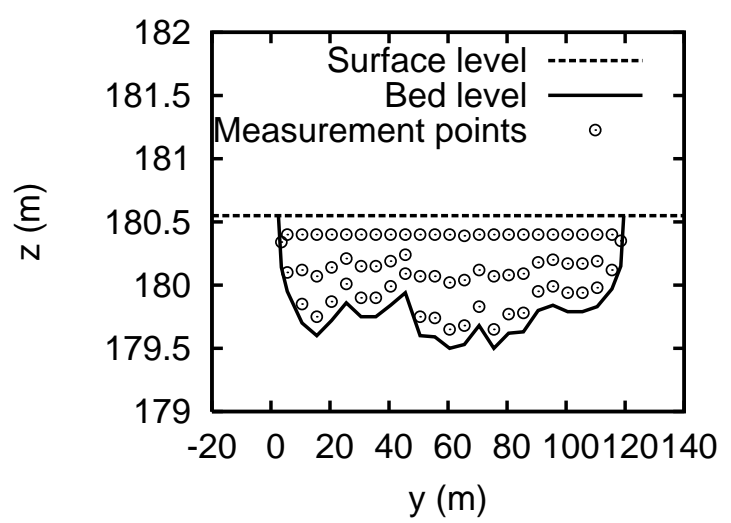

(b)

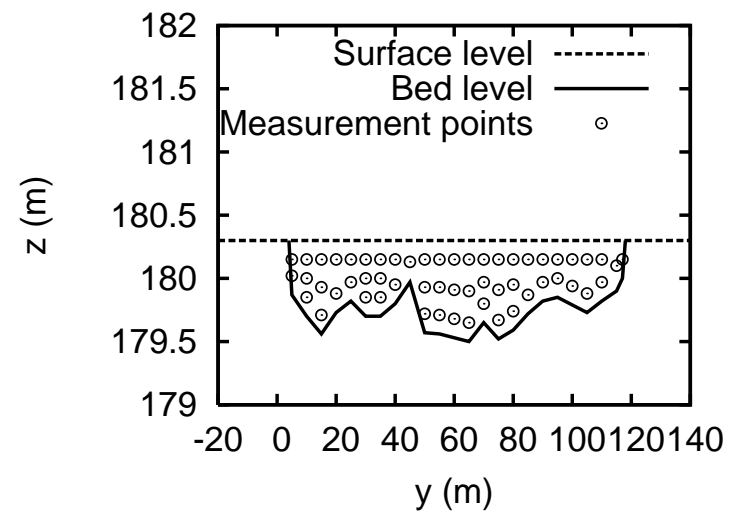

(c)

Figure 14: Sketch of velocity measured points in the Ebro River cross section for discharges of (a) $147 \mathrm{~m}^{3} / \mathrm{s},(\mathrm{b}) 68 \mathrm{~m}^{3} / \mathrm{s}$ and (c) $26 \mathrm{~m}^{3} / \mathrm{s}$. 


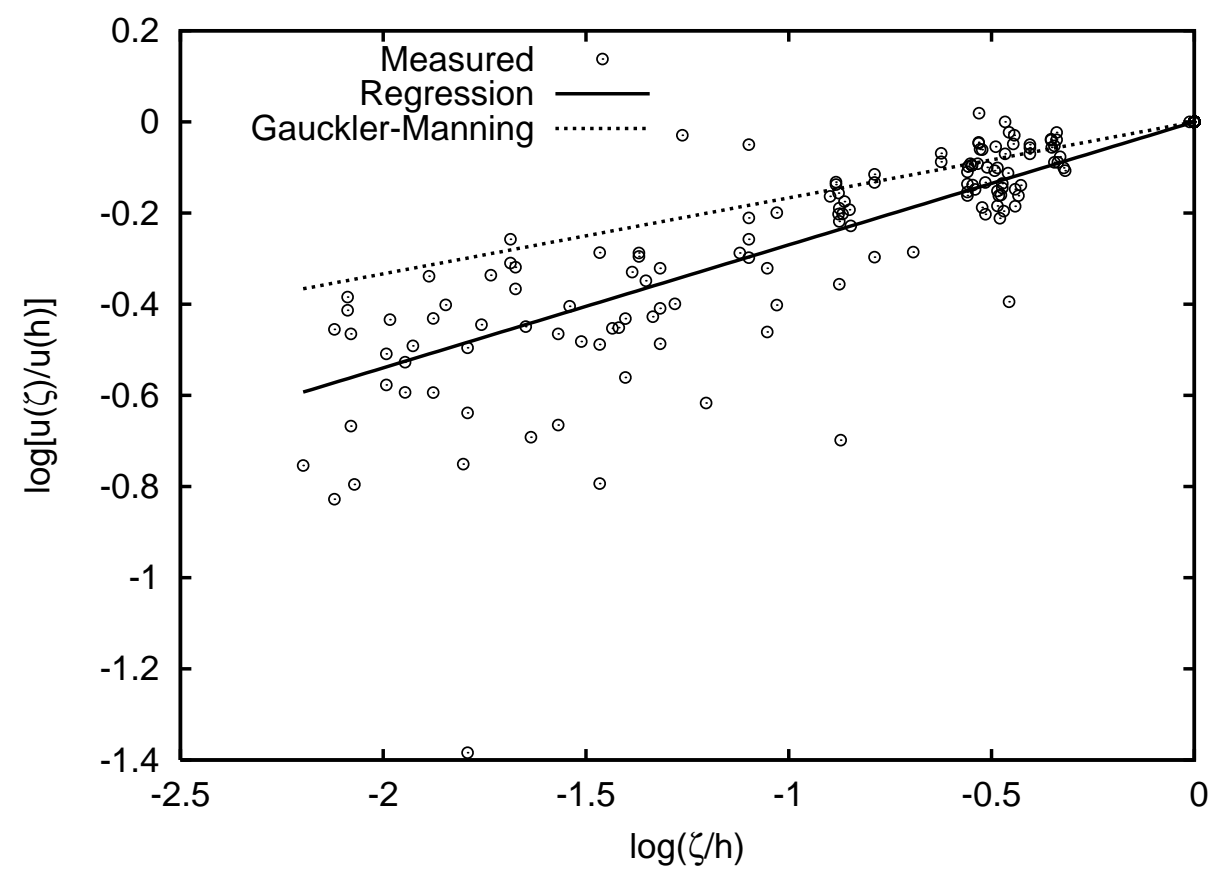

Figure 15: Comparison of the velocity ratio versus vertical coordinate ratio regressions and measurents in the Ebro River cross section. 


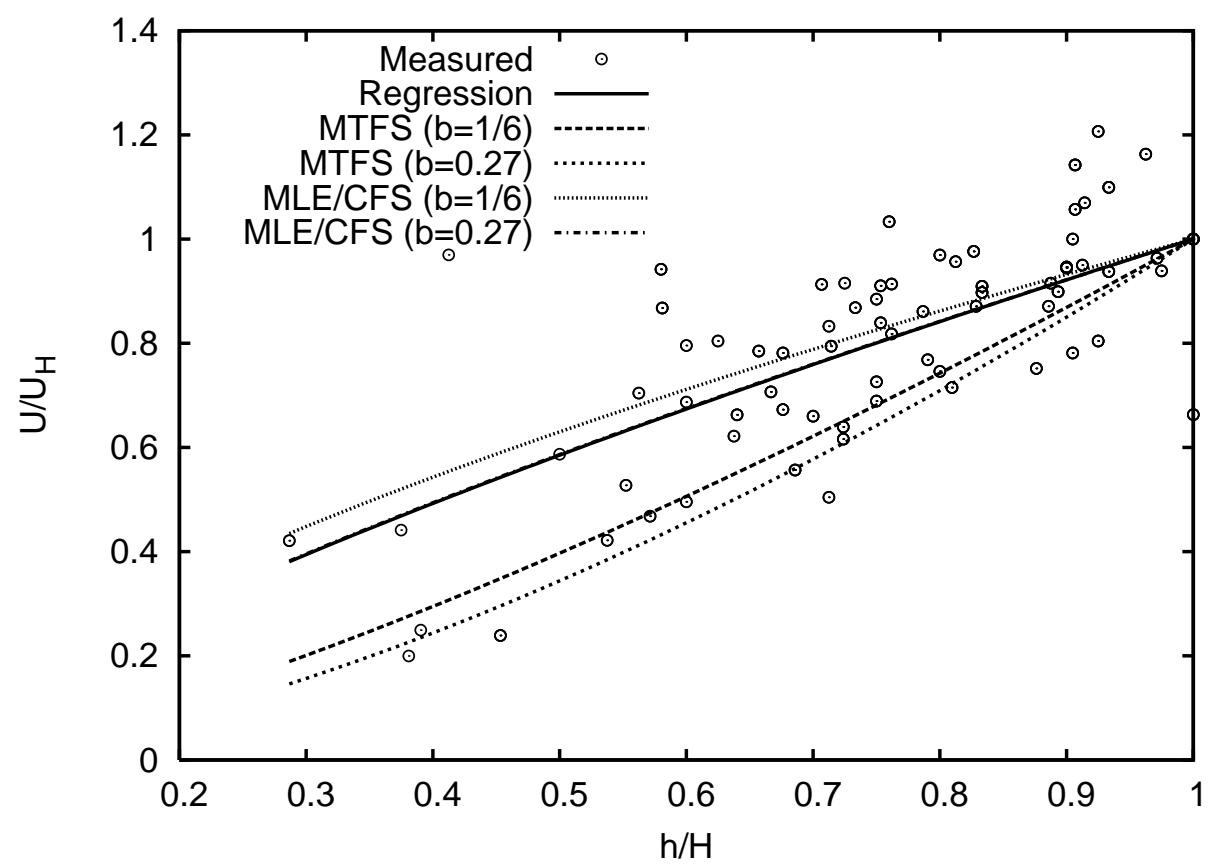

Figure 16: Linear regression of the depth-averaged water velocity in terms of the water depth in the Ebro River cross section. 


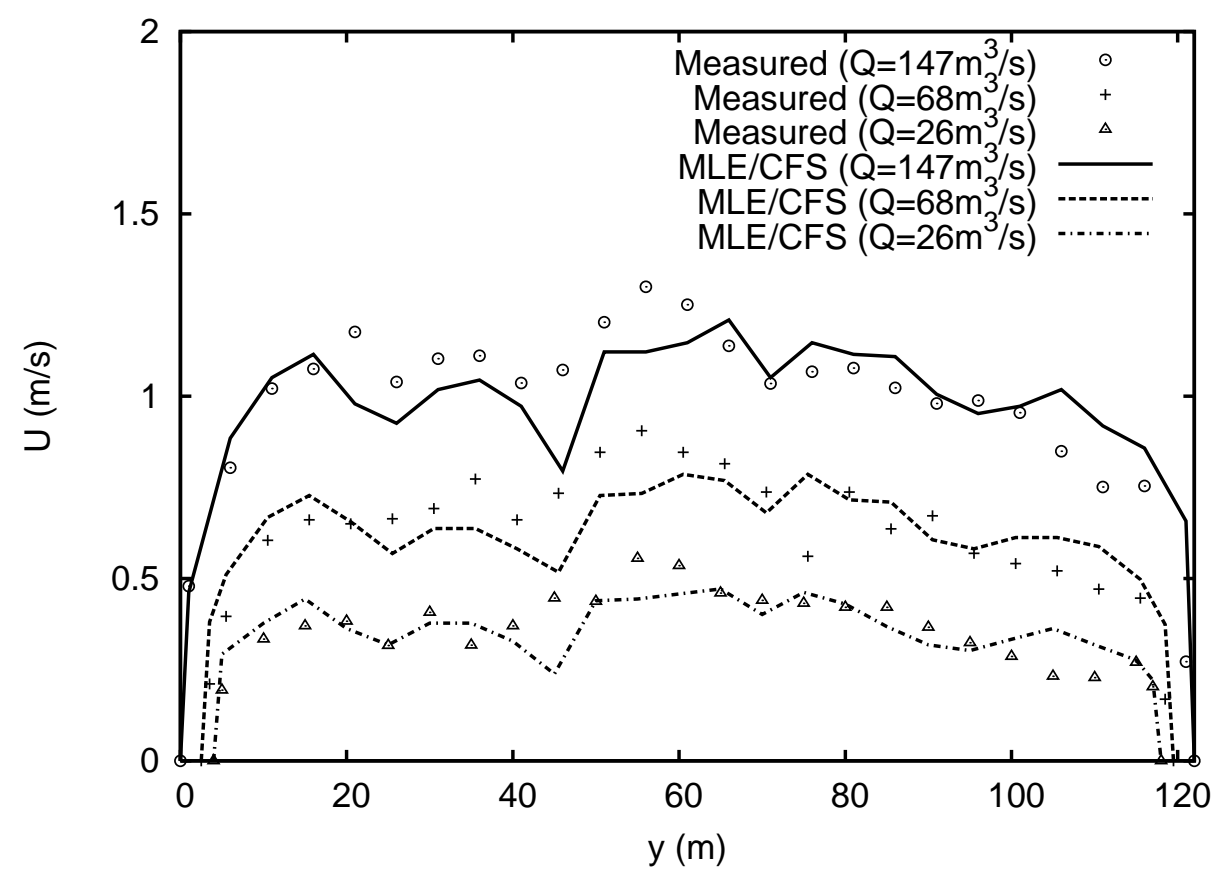

(a)

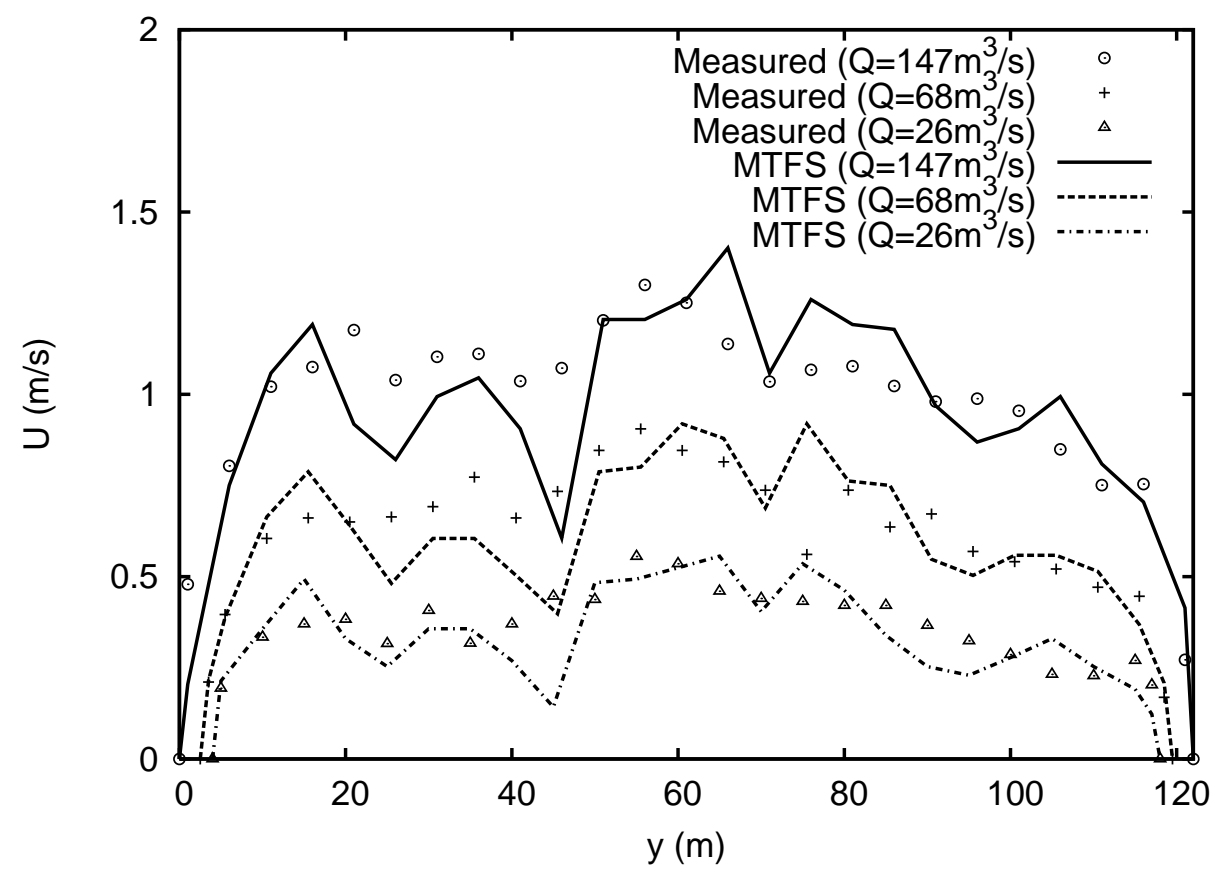

(b)

Figure 17: Depth-averaged water velocity measured and predicted by (a) MLE/CFS, (b) MTFS models with $b=0.27$ in the Ebro River cross section. 


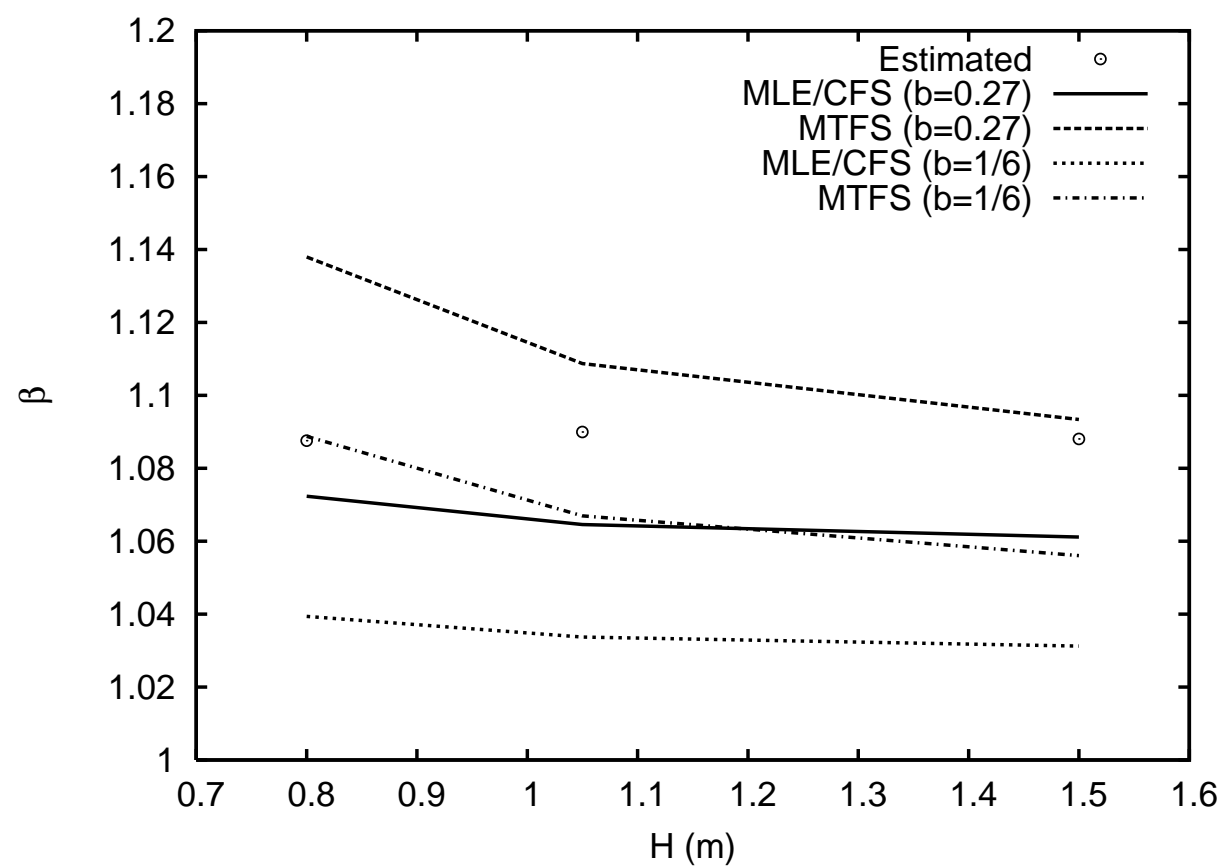

Figure 18: Comparison of $\beta$ coefficient versus depth estimated by measures and predicted by models in the Ebro River cross section. 


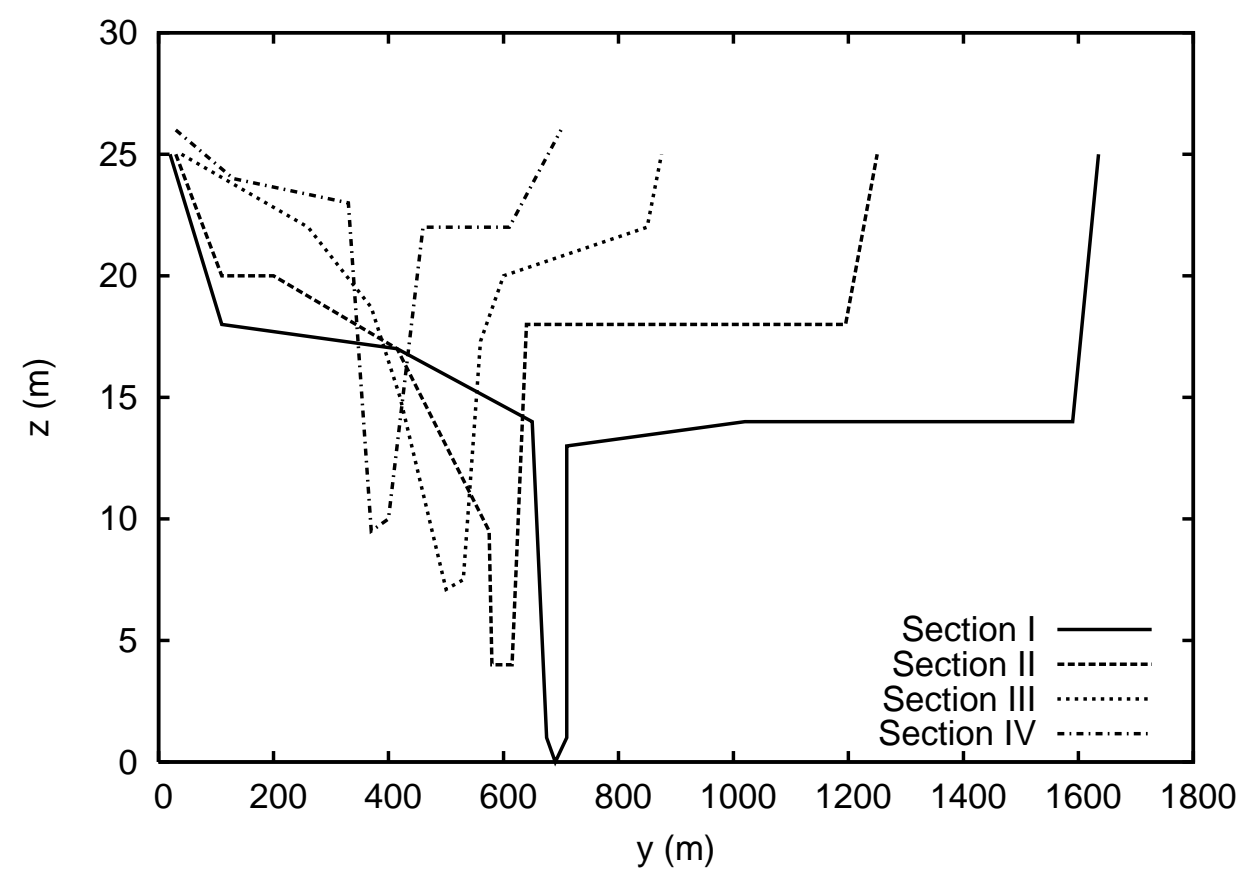

Figure 19: Cross sectional form of four typical Ebro River sections. 


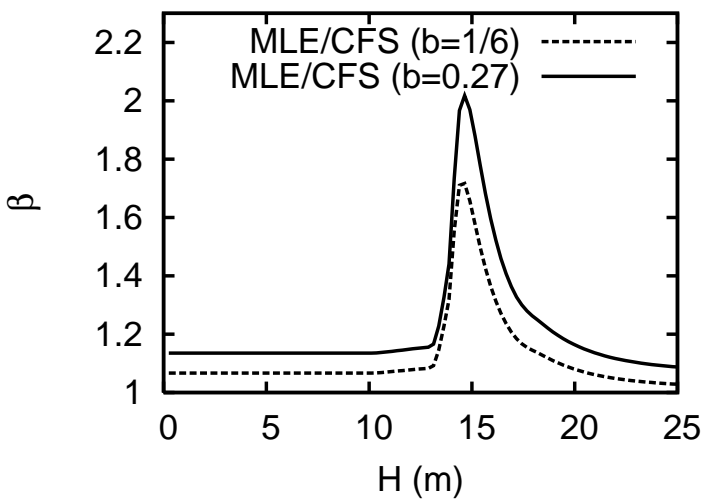

(a)

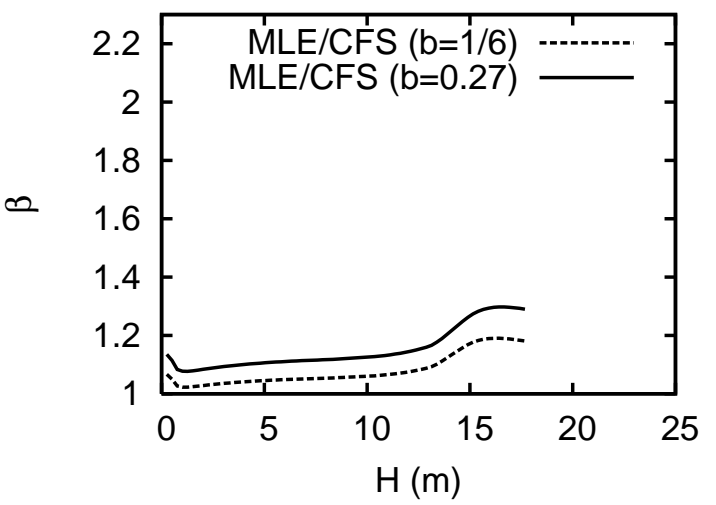

(c)

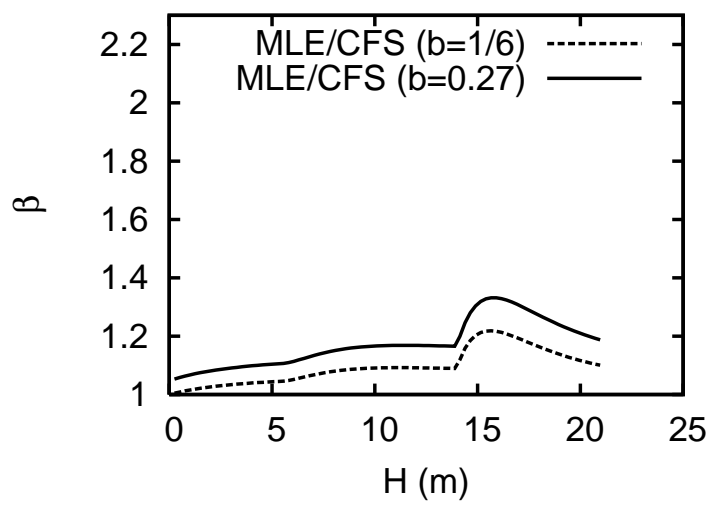

(b)

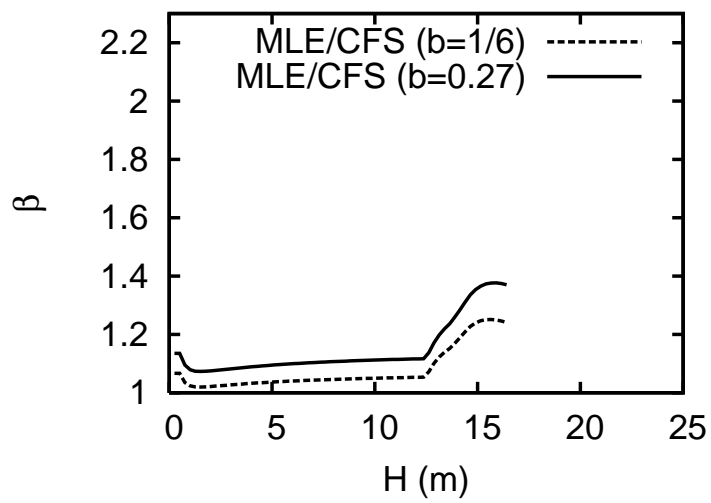

(d)

Figure 20: Values of the $\beta$ coefficient as a function of the water depth calculated using the MLE/CFS model with different $b$ values: (a) section I, (b) section II, (c) section III and (d) section IV. 


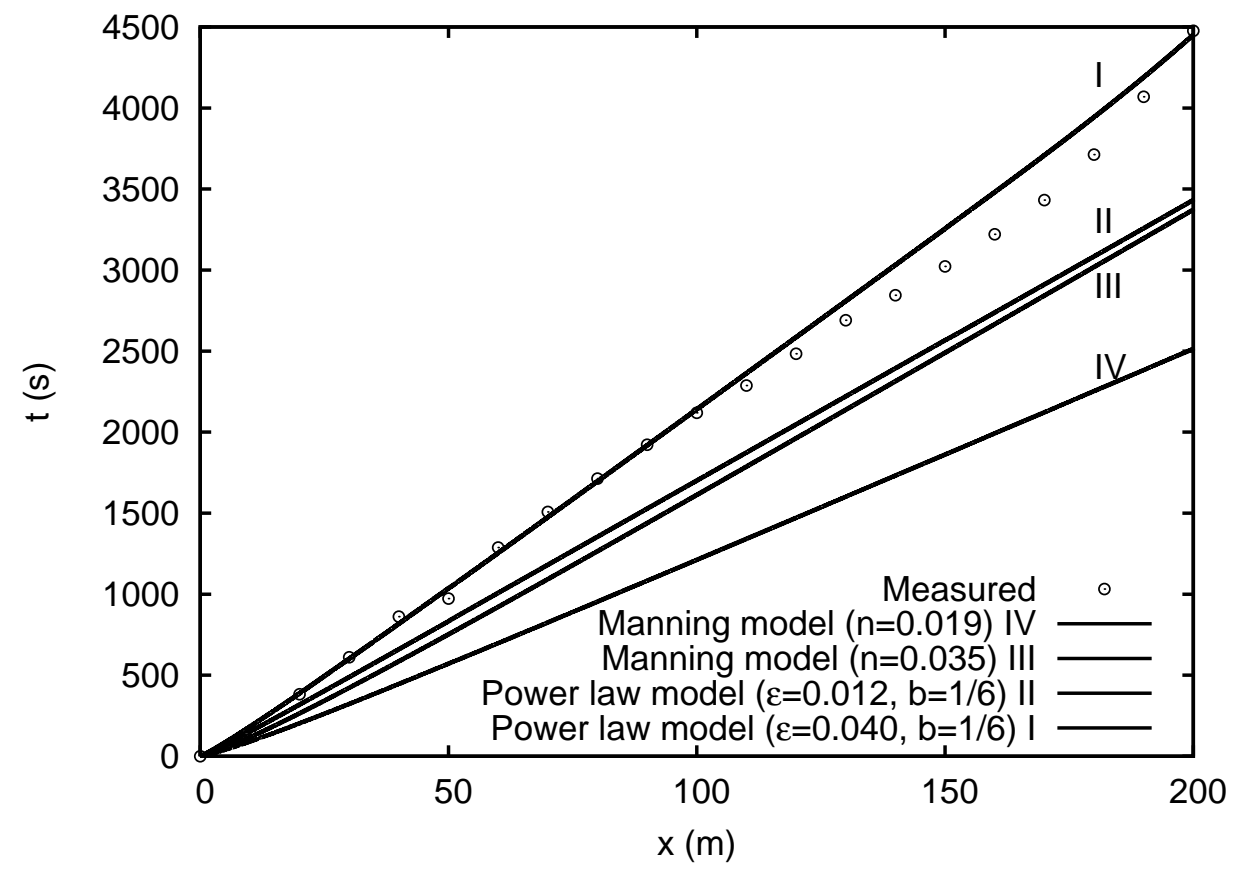

(a)

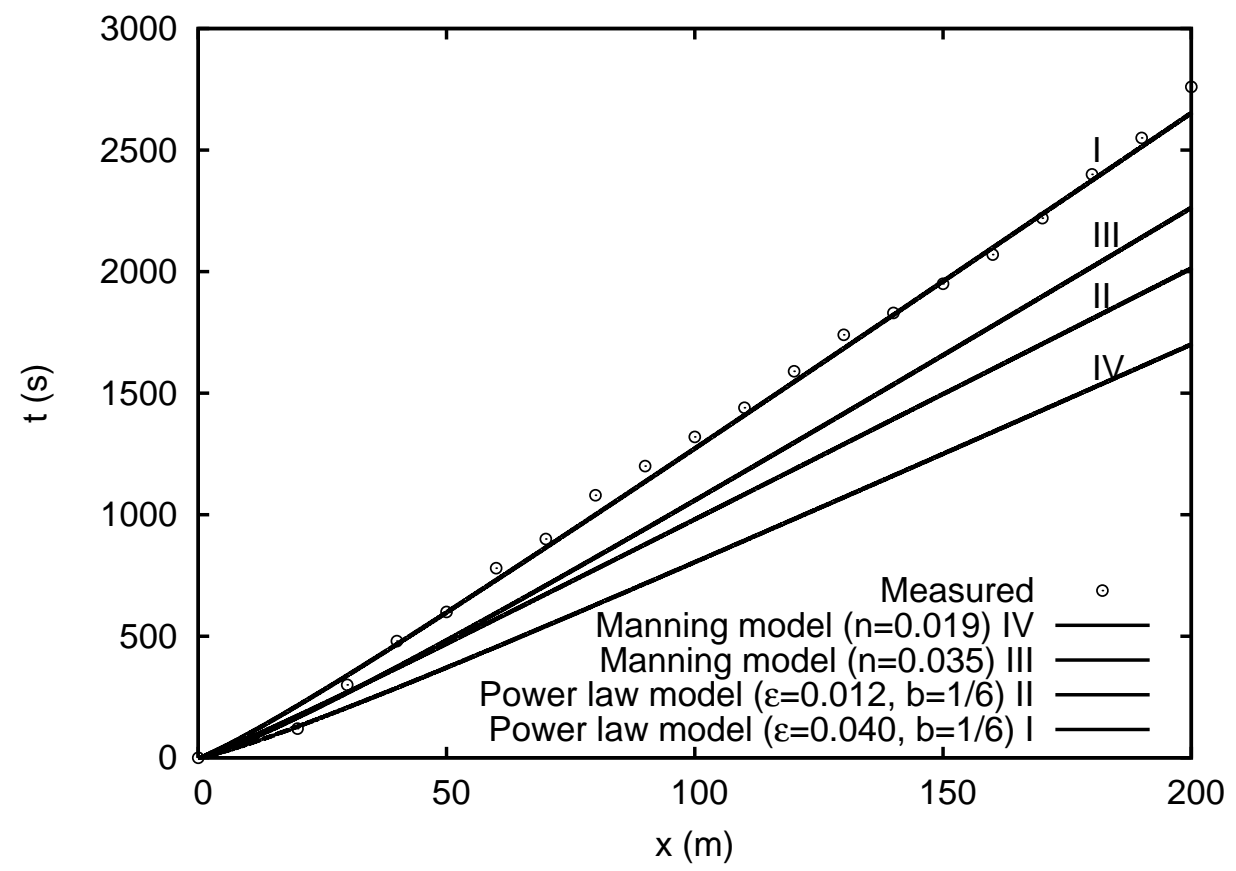

(b)

Figure 21: Advance curves with $\delta x=0.2 \mathrm{~m}$ and discharges of (a) $Q=0.0047 \mathrm{~m}^{3} / \mathrm{s}$ and (b) $Q=0.0117 \mathrm{~m}^{3} / \mathrm{s}$. 


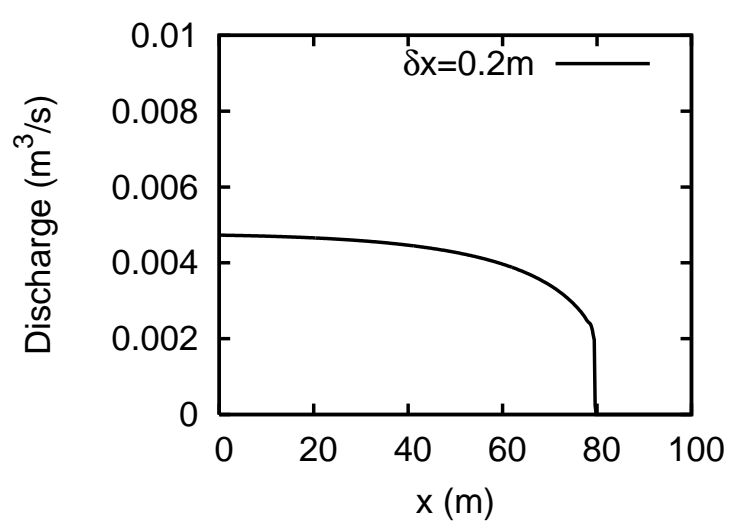

(a)

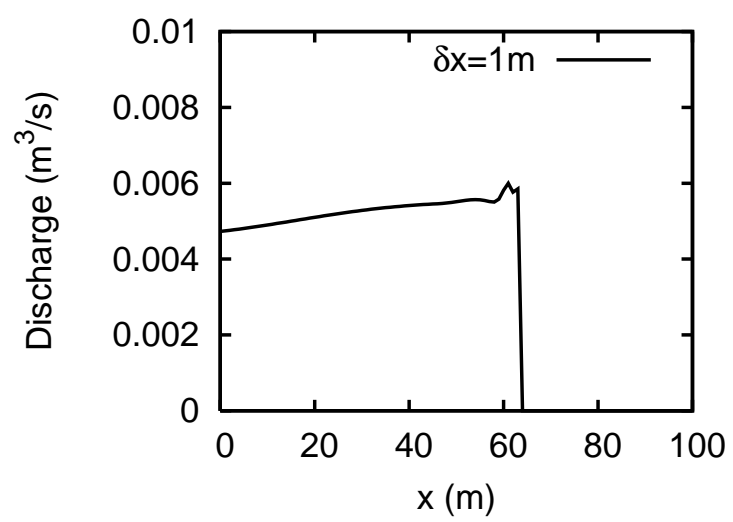

(c)

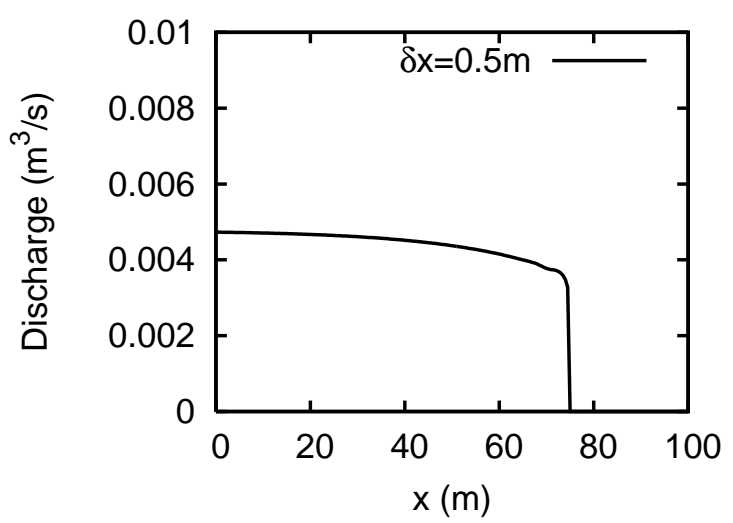

(b)

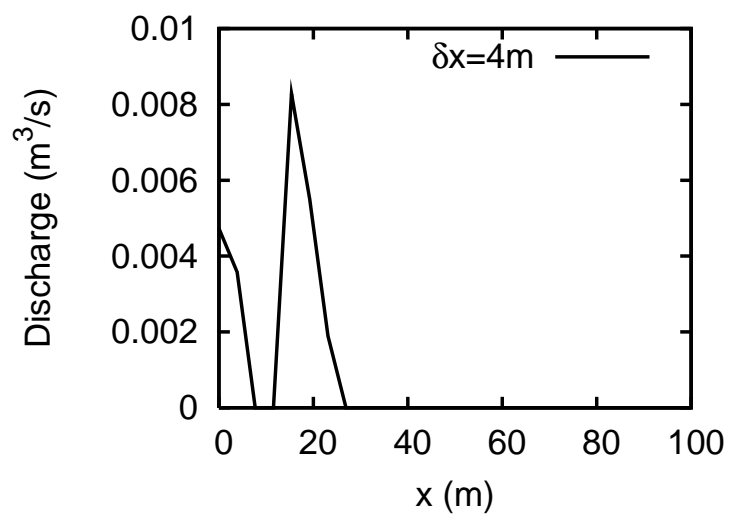

(d)

Figure 22: Longitudinal discharge profiles corresponding to advancing time $t=1200 \mathrm{~s}$ with $Q=$ $0.0047 \mathrm{~m}^{3} / \mathrm{s}$ and different values of $\delta x$. Gauckler-Manning model with $n=0.035 \mathrm{~s} \cdot \mathrm{m}^{-1 / 3}$ was used. 